\title{
AUTORADIOGRAPHIC LOCALIZATION OF CHOLECYSTOKININ RECEPTORS IN RODENT BRAIN ${ }^{1}$
}

\author{
M. A. ZARBIN, R. B. INNIS, J. K. WAMSLEY, S. H. SNYDER, AND M. J. KUHAR ${ }^{2}$
}

Departments of Neuroscience, Pharmacology and Experimental Therapeutics, and Psychiatry and the Behavioral Sciences, The Johns Hopkins University School of Medicine, Baltimore, Maryland 21205

Received June 25, 1982; Revised October 14, 1982; Accepted October 15, 1982

\begin{abstract}
Cholecystokinin (CCK) receptor binding sites have been localized by autoradiography in the guinea pig and rat central nervous system. $\left.{ }^{125} \mathrm{I}\right]$ CCK-triacontatriapeptide labeled the sites in brain slices with an observed association constant equal to $0.041 \mathrm{~min}^{-1}$ and a dissociation constant equal to $0.008 \mathrm{~min}^{-1}$. CCK-triacontatriapeptide (CCK-33) and the C-terminal octapeptide of CCK-33 (CCK-8) potently inhibited $\left.{ }^{125} \mathrm{I}\right] \mathrm{CCK}-33$ binding with $K_{i}$ 's of $2 \mathrm{nM}$, whereas desulfated CCK-8 (CCK8-ds) and the C-terminal tetrapeptide of CCK-33 (CCK-4) were much weaker. Receptors were concentrated in the olfactory bulb, in the superficial laminae of the primary olfactory cortex, in the deep laminae of the cerebral cortex, and in the pretectal area. Substantial numbers of sites were also found in the basal ganglia, in the amygdala, and in the hippocampal formation. $\left[{ }^{125} \mathrm{I}\right] \mathrm{CCK}-33$ binding sites appear to be located on fibers of the optic tract and probably on olfactory tract fibers as well. These results are discussed in terms of physiological functions associated with CCK, presynaptic receptors, and axonal flow of CCK receptors.
\end{abstract}

For many years cholecystokinin (CCK), a 33-amino acid peptide, has been recognized as an intestinal hormone involved in the regulation of gallbladder and pancreatic function (Ivy and Oldberg, 1928; Harper and Raper, 1943; Mutt and Jorpes, 1966). Recently, Dockray (1976), Rehfeld (1977), and Strauss and Yalow (1978) reported the existence of CCK-like immunoreactivity in the brain. Shortly thereafter, CCK-like material was localized in neurons by immunohistochemistry (Larsson and Rehfeld, 1979; Innis et al., 1979; Loren et al., 1979; Vanderhaeghen et al., 1980), and binding sites for radiolabeled CCK were detected in the brain (Saito et al., 1980, 1981a; Innis and Snyder, 1980a, b; Hays et al., 1980). Presently, a substantial body of evidence supports the notion that CCK may act as a neurotransmitter in the CNS (see Rehfeld, 1980, for review). In an earlier autoradiographic study, we described the laminar distribution of $\left.{ }^{125} \mathrm{I}\right] \mathrm{CCK}$-triacontatriapeptide (CCK-33) binding sites in the guinea pig cingulate cortex and in other forebrain

\footnotetext{
${ }^{1}$ We wish to acknowledge the technical assistance of Mrs. Theresa Kopajtic and Mrs. Naomi Taylor and the clerical assistance of Ms. Darlene Weimer and Mrs. Mary Flutka. Research was supported by grants from the McKnight Foundation, Research Center Development Award and Type II Awards MH 00053 and MH 25951 (M. J. K.), Medical Scientist Training Program Award GM 07309 (M. A. Z.) and Grant DA 00266 and Research Scientist Award DA 00074 (S. H. S.)

${ }^{2}$ To whom correspondence should be addressed at Department of Neuroscience, The Johns Hopkins University School of Medicine, 725 N. Wolfe Street, Baltimore, MD 21205.
}

areas (Zarbin et al., 1981b). In this communication, a more detailed description of that distribution is presented, and additional findings in the guinea pig and rat are reported. These autoradiographic studies have been undertaken to develop data which may indicate the CNS loci whose function CCK alters.

\section{Materials and Methods}

Binding sites for cholecystokinin were localized by in vitro receptor autoradiography. This quantitative technique (Unnerstall et al., 1981) can be used to determine the anatomical distribution of the binding sites of diffusible substances. The details of the procedure have been described elsewhere (Young and Kuhar, 1979). Briefly, thaw-mounted frozen tissue sections of rodent brain were incubated in vitro in conditions which are optimal for labeling the binding site of interest with pharmacological specificity and maximal specific/nonspecific binding ratios. Subsequently, the tissue sections are dried and apposed against emulsion-coated glass coverslips. After an appropriate exposure time, the photographic emulsion is developed and the autoradiograms are veiwed using an ordinary light microscope. Additional details are as follows:

Tissue preparation. Male guinea pigs (Hartley, Tomkins Cove, NY, 250 to $300 \mathrm{gm}$ ) or rats (SpragueDawley, Madison, WI, 180 to $250 \mathrm{gm}$ ) were anesthetized with pentobarbitol (guinea pig: $30 \mathrm{mg} / \mathrm{kg}$, i.p.; rat: $60 \mathrm{mg} /$ $\mathrm{kg}$, i.p.) and perfused intracardially with 300 to $500 \mathrm{ml}$ of 
$0.1 \%$ formaldehyde (Fisher, Fairlawn, NJ) in cold phosphate-buffered saline, pII 7.4, for 10 to $15 \mathrm{~min}$. The light fixation of the tissue was found to have no adverse effect on $\left[{ }^{125} \mathrm{I}\right]$ CCK -33 binding. The brains were then rapidly dissected, mounted onto brass microtome chucks, and frozen in liquid nitrogen. The material was sectioned $(8$ $\mu \mathrm{m}$ ) on a Harris cryostat microtome (Harris Manufacturing Co., N. Billerica, MA), thaw-mounted onto subbed glass microscope slides, and stored at $-20^{\circ} \mathrm{C}$. Tissue prepared in this way was stored for as long as 2 months without significant alterations in CCK binding.

Receptor binding. ${ }^{125} \mathrm{I}$ Bolton Hunter-labeled CCK-33 ([ $\left.{ }^{125} \mathrm{I}\right] \mathrm{CCK}-33$ ) was routinely used to label CCK binding sites. The radioactive ligand was prepared according to the method of Sankaran et al. (1980). Chromatographic analysis indicated that the ligand was stable and retained full binding capacity for at least $1 \mathrm{hr}$ in the incubation conditions described below.

Slide-mounted tissue sections were brought to room temperature and incubated at $25^{\circ} \mathrm{C}$ in a buffer solution containing $50 \mathrm{~mm}$ Tris- $\mathrm{HCl}, \mathrm{pH} \mathrm{7.7,0.2 \%}$ bovine serum albumin (Fraction V, Sigma), $5 \mathrm{~mm} \mathrm{MgCl}, 5 \mathrm{~mm}$ dithiothreitol, $0.1 \mathrm{~mm}$ bacitracin, and $\left.50 \mathrm{pm}\left[{ }^{125} \mathrm{I}\right] \mathrm{CCK}-33 .{ }^{125} \mathrm{I}\right]$ CCK-33 binding in the presence of $10^{-7} \mathrm{M}$ CCK-8 (the Cterminal octapeptide of CCK-33) was used to estimate nonspecific binding. In membrane homogenate studies, the CCK binding site labeled in these conditions has been shown to have biochemical and pharmacological characteristics expected of the physiologically relevant CCK receptor (Innis and Snyder, 1980a, b). After the incubation was complete, the tissue sections were rinsed in buffer $\left(4^{\circ} \mathrm{C}\right.$ ), dipped in deionized distilled $\mathrm{H}_{2} \mathrm{O}$ (to eliminate tissue-bound salts), and dried in a stream of cool, dry air. In preliminary nonautoradiographic binding studies, the tissue sections were not dried. Instead, the tissue was wiped off the glass microscope slide with Whatman GF-B3 filter paper (Whatman, Ltd., England), and the filter-associated radioactivity was assayed in a gamma counter.

To ascertain whether endogenous CCK-like peptides could compete with [ $\left.{ }^{125} \mathrm{I}\right] \mathrm{CCK}-33$ for the CCK binding site, slide-mounted tissue sections were pre-incubated in buffer at $25^{\circ} \mathrm{C}$ for $20 \mathrm{~min}$, washed for $5 \mathrm{~min}$ at $25^{\circ} \mathrm{C}$ in fresh buffer, and then assayed for CCK binding. $\left.{ }^{125} \mathrm{I}\right]$ CCK-33 binding to pre-incubated tissue sections did not seem to differ from binding to nonpre-incubated consecutive tissue sections. Thus, the pre-incubation step was not included in most autoradiographic experiments. Kinetic curves and pharmacological displacement curves were drawn by visual inspection.

Autoradiography. Autoradiographic experiments were carried out as described previously (Young and Kuhar, 1979; Palacios et al., 1980). The emulsion-coated coverslips were exposed to the tissue-bound radioactivity for 8 to 12 weeks. After this time, emulsion was developed, and the autoradiograms were viewed using a Zeiss Universal microscope or an Olympus darkfield/brightfield dissecting microscope (Olympus Optical Co., Ltd., NY). When desired, grain densities were quantified using the Zeiss scope and an eyepiece equipped with a superimposed grid.

Chemicals. CCK-33 was the generous gift of Dr. V. Mutt (Karolinska Institute, Sweden). CCK-4 was kindly provided by Dr. L. I. Larsson (University of Aarrus, Denmark), and CCK -8 and desulfated CCK-8 (CCK-8ds) were the gifts of Dr. M. Ondetti (E. R. Squibb, Princeton, $\mathrm{NJ})$.

\section{Results}

Before generating autoradiograms, preliminary biochemical experiments were performed to determine appropriate experimental conditions for labeling CCK binding sites in slide-mounted tissue sections. Experiments designed to examine the pharmacological characteristics of the binding were also carried out.

Kinetic analysis of $\left[^{125} I\right] C C K-33$ binding to guinea pig brain. The rate of dissociation of $\left[{ }^{125} \mathrm{I}\right] \mathrm{CCK}-33$ from slidemounted tissue sections of guinea pig forebrain was de-

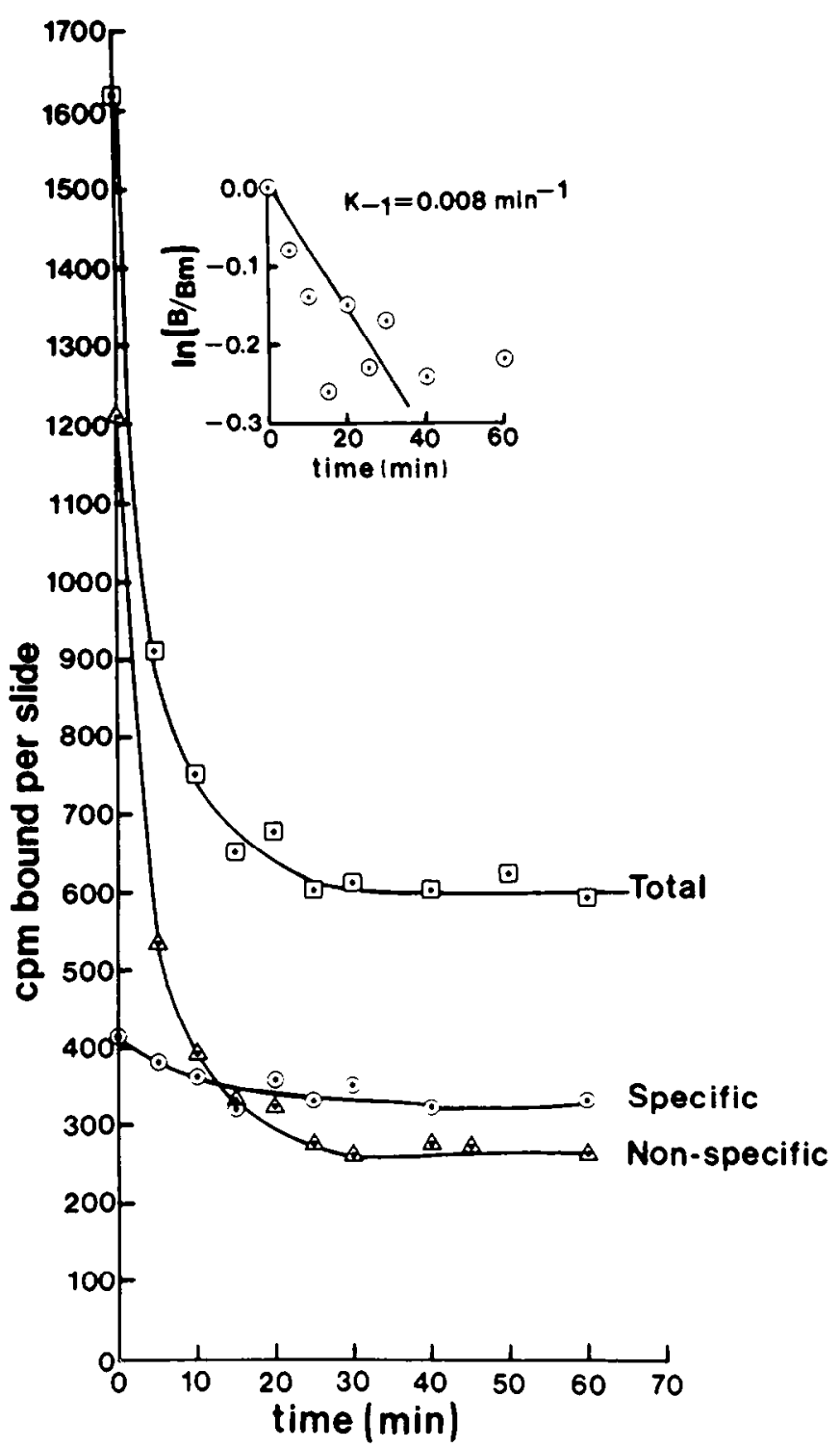

Figure 1. Time course of dissociation of $\left[{ }^{125} \mathrm{I}\right] \mathrm{CCK}-33$ binding $\left(22^{\circ} \mathrm{C}\right)$ from slide-mounted tissue sections $(8 \mu \mathrm{m})$ of guinea pig forebrain. Nonspecific binding (binding in the presence of $10^{-7}$ M CCK-8) is represented as $\triangle$. Specific binding $(O)$ is defined as the difference between total $(\square)$ and nonspecific binding. The points are the average of three determinations with less than $15 \%$ differences among the samples. Inset shows the dissociation rate of specific binding: $K_{-1}=0.008 \mathrm{~min}^{-1} . \mathrm{B} / \mathrm{Bm}=$ specific binding/maximal specific binding. 


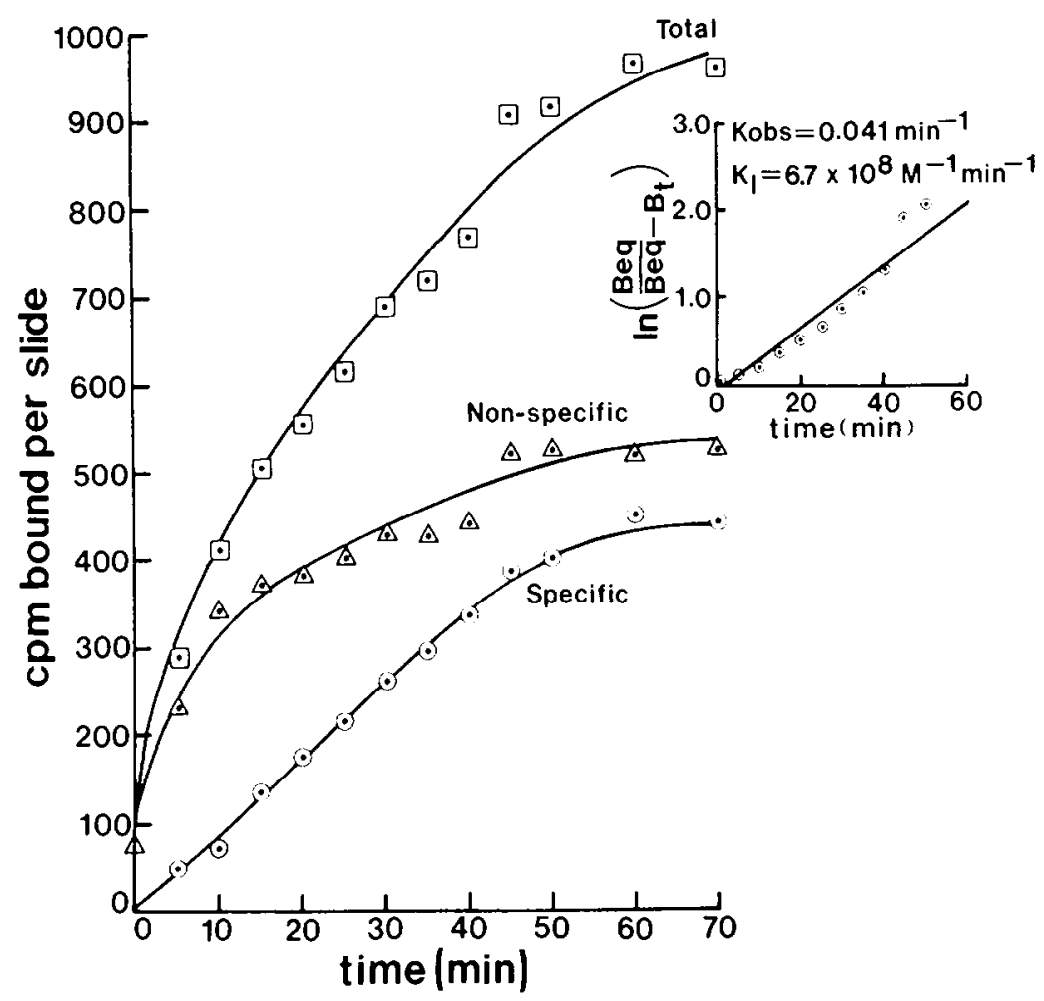

Figure 2. Time course of association of $\left[{ }^{125} \mathrm{I}\right] \mathrm{CCK}-33\left(22^{\circ} \mathrm{C}\right)$ to slide-mounted tissue sections $(8 \mu \mathrm{m})$ of guinea pig brain. Specific binding $(O)$ is defined as the difference between total binding $(\square)$ and binding in the presence of $10^{-7} \mathrm{M}$ CCK $-8(\triangle)$. The wash time for all observations was $30 \mathrm{~min}\left(22^{\circ} \mathrm{C}\right)$. Each point is the average of three determinations which differed by less than $15 \%$. Inset shows the association binding kinetics: Kobs $=0.041 \mathrm{~min}{ }^{1} ; K_{1}=6.7 \times 10^{8} \mathrm{M}^{-1} \mathrm{~min}^{-1}$. Beq/Beq.B equilibrium/specific binding at equilibrium-specific binding at time $t$.

termined. The tissue was incubated for $60 \mathrm{~min}$ at room temperature with $50 \mathrm{pM}\left[{ }^{125} \mathrm{I}\right] \mathrm{CCK} \cdot 33$ and then washed for varying times in buffer at $4^{\circ} \mathrm{C}$. Some tissue sections were incubated in the presence of $10^{-7} \mathrm{M}$ CCK -8 to determine nonspecific binding. After $30 \mathrm{~min}$ of rinsing (Fig. 1), the nonspecific binding decreased by $84 \%$. The specific binding, on the other hand, had decreased by only $22 \%$. Because both the specific and nonspecific binding decreased only very slowly after $30 \mathrm{~min}$ of rinsing, and because the specific to nonspecific binding ratio (1.4:1) was maximal at this time, 30-min rinses were used in subsequent experiments. The dissociation constant $\left(0.008 \mathrm{~min}^{-1}\right)$ was comparable to that observed in similar experimental conditions by others (Saito et al., 1981a, b; Hays et al., 1980).

To determine the rate of association of $\left.{ }^{125} \mathrm{I}\right] \mathrm{CCK}-33$ to slide-mounted tissue sections of guinea pig forebrain, slides were incubated for various times at room temperature and rinsed as described above. After an incubation time of $15 \mathrm{~min}$, the nonspecific binding had achieved $85 \%$ of its maximum value, whereas the specific binding had achieved only $30 \%$ of its maximum. After $50 \mathrm{~min}$, neither the specific nor the nonspecific binding increased significantly (Fig. 2). Thus, incubation times of $50 \mathrm{~min}$ were used in subsequent experiments. Incubations of greater duration were avoided because of the ligand's propensity to decay with longer incubation times (Hays et al., 1980). The observed association constant $\left(0.041 \mathrm{~min}^{-1}\right)$ is in very good agreement with that derived from membrane homogenate studies (Hays et al., 1980; Saito et al., 1980, 1981a).
Pharmacological specificity of $\left.{ }^{125} I\right] C C K-33$ binding (Fig. 3). CCK-33 and CCK-8 potently displaced [ $\left.{ }^{125} \mathrm{I}\right]$ CCK-33 binding with $K_{i}$ 's of $2 \mathrm{nM}$, whereas desulfated CCK-8 (CCK-8ds) was substantially less potent ( $K_{i}=37$ nM). CCK- 4 was the least potent displacer analyzed with an $\mathrm{IC}_{50}$ of at least $100 \mathrm{~nm}$. The pseudo Hill coefficients derived from the competition studies were close to unity for each inhibitor. These data are in close agreement with those of membrane homogenate studies (Hays et al., 1980; Innis and Snyder, 1980a, b; Saito et al., 1980, 1981a). The binding constant for CCK-33 that was derived from equilibrium experiments was greater than that determined by kinetic analysis. Although the reason for this discrepancy is not apparent at the present time, this phenomenon has also been observed in membrane homogenate studies (Innis and Snyder, 1980a; Hays et al., 1980). In any case, the binding sites labeled in the slidemounted tissue sections clearly have pharmacological characteristics of a relevant CCK receptor.

Autoradiographic studies (Table I). Eight-micron sections of guinea pig or rat brain were incubated in $50 \mathrm{pm}$ $\left[{ }^{125} \mathrm{I}\right] \mathrm{CCK}-33$ for $50 \mathrm{~min}$, washed for $30 \mathrm{~min}$, and dried as described under "Materials and Methods." This report will focus mostly on results obtained in the guinea pig, although findings in the rat will be mentioned. The results obtained in the olfactory lobe are summarized in Table II, while all other areas are summarized in Table III.

Olfactory lobe (Table II). The principal findings are the presence of an extremely high grain density in the external plexiform layer (EPL) of the main and accessory 


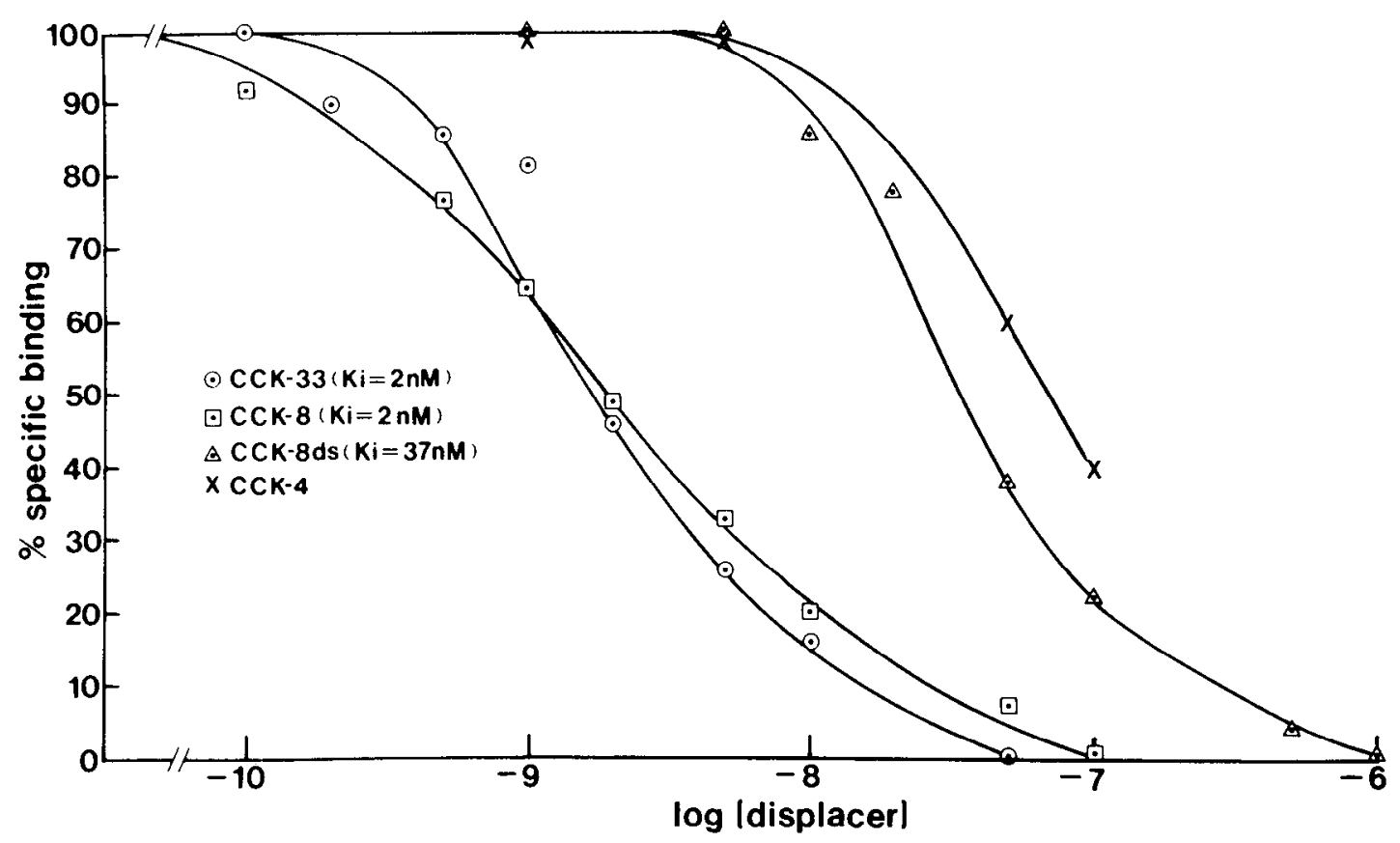

Figure 3. Pharmacology of $\left[{ }^{125} \mathrm{I}\right] \mathrm{CCK}-33$ binding to tissue sections $(8 \mu \mathrm{m})$ of guinea pig forebrain. Incubations were carried out at $22^{\circ} \mathrm{C}$ for $50 \mathrm{~min}$ in the presence of varying concentrations of displacers. The tissue sections were then rinsed in buffer at $4^{\circ} \mathrm{C}$ for $30 \mathrm{~min}$. The bound radioactivity was determined in a gamma counter. Each value is the average of three determinations which differed by less than $10 \%$. See the text for details.

\section{TABLE I}

Relationship between grain density rating and actual grain density

Autoradiographic grain counts were made using a $\times 100$ oil immersion objective on a Zeiss microscope equipped with a grid-containing eyepiece. Absolute grain densities were derived from autoradiograms which were exposed for 8 weeks. Material from two animals (guinea pigs) was analyzed in this quantitative fashion. Within a given animal, the grain density over each anatomical locus was taken to be the average of six determinations. Because the interanimal variation in grain density was not large in most regions ( $<20 \%$ variation), the remaining material $(n=4)$ was reviewed qualitatively in an Olympus brightfield-darkfield dissection microscope and in the Zeiss microscope. Nonspecific grain densities (defined as binding in the presence of $10^{-7}$ M CCK-8) was usually less than 5 grains $/ 95 \mu \mathrm{m}^{2}$.

\begin{tabular}{cc}
\hline Relative Grain Density Rating & Absolute Grain Density \\
\hline & grains $/ 95 \mu m^{2}$ \\
3 & $40-80$ \\
2 & $20-40$ \\
1 & $5-20$ \\
\hline
\end{tabular}

olfactory bulbs and the presence of a high grain density over areas which are traversed by fibers of the lateral olfactory tract (LOT).

In the rostral part of the olfactory bulb (Fig. 4), the
TABLE II

Distribution of CCK binding sites in the guinea pig olfactory bulb See Table I for the correlation between grain density and the relative density ratings $(1,2,3$, or 4$)$. The data are based on observations in at least three animals. The terminology used follows that of Lohman (1963). See the text for details.

\begin{tabular}{lcc}
\hline \multirow{2}{*}{ Area } & \multicolumn{2}{c}{$\begin{array}{c}\text { Relative Density of Autoradiographic } \\
\text { Grains }\end{array}$} \\
\cline { 2 - 3 } & Main Bulb & Accessory Bulb \\
\hline Glomerular layer & 2 & 3 \\
External granular layer & 2 & 2 \\
External plexiform layer & $4+$ & $4+$ \\
Mitral cell layer & 4 & 4 \\
Internal plexiform layer & & $4+$ \\
Internal granule cell layer & $3+$ & $3+$ \\
\hline
\end{tabular}

grain density over the EPL was the highest observed in the guinea pig brain. Within the EPL, the density appeared to be higher in the middle portion of the lamina (as opposed to areas close to the glomerular and mitral cell layers). The grain density in the mitral cell layer of the accessory bulb appeared somewhat higher than that in the main bulb. Within the lamina, grains were found over the neuropil and over large cells which were mor-

Figure 4. Distribution of CCK binding sites in the guinea pig olfactory bulb. A, Brightfield photomicrograph of an autoradiogram at the level of the olfactory bulb (coronal plane). At this magnification, as in all other brightfield photos which occur in subsequent figures, the autoradiographic grains cannot be visualized. $B$, Darkfield photomicrograph of the autoradiogram shown in $A$. In darkfield illumination, the autoradiographic grains appear as white spots and the tissue is invisible. Some areas of low to intermediate grain density may not be easily discernible in these low magnification, high contrast photos, although they are described in Table III. This caveat applies to the photos in subsequent figures as well. As a result, in this and following figures, the photo gives only a qualitative indication of grain density. $C$, Darkfield photomicrograph of an autoradiogram generated from a tissue section consecutive to the one shown in $A$ in which 50 pM $\left[{ }^{125} \mathrm{I}\right] \mathrm{CCK}-33$ was co-incubated with $10^{-7} \mathrm{M}$ CCK-8. The low density of grain suggests that the nonspecific binding in the assay is rather low. The arrowheads indicate the location of various anatomical structures. $E P L$, external plexiform layer; $I P L$, internal plexiform layer; $G$, glomerular layer; $G R$, inner granule layer. See the text for discussion. Bar $=2300 \mu \mathrm{m}$. 

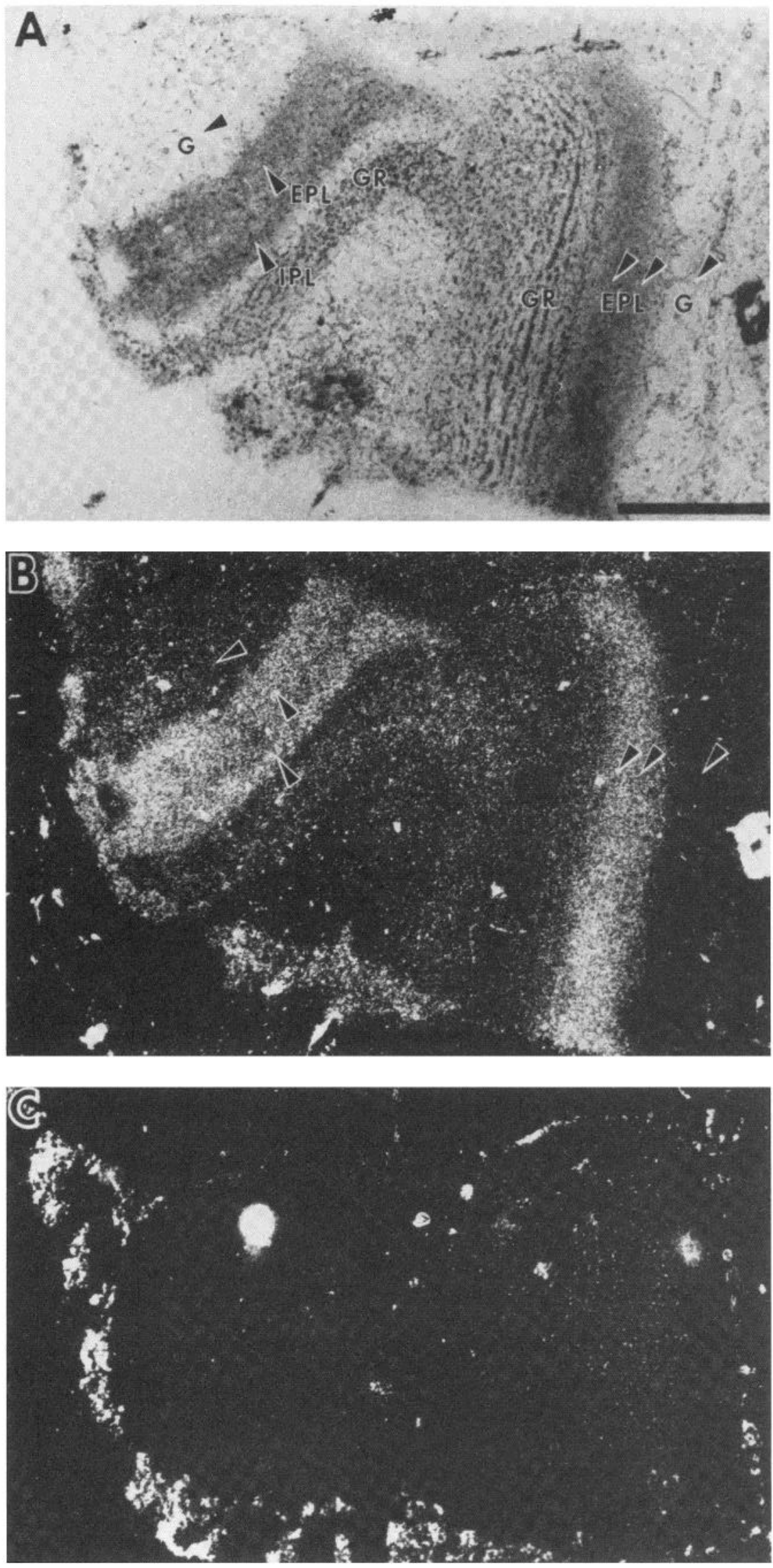

Figure 4 

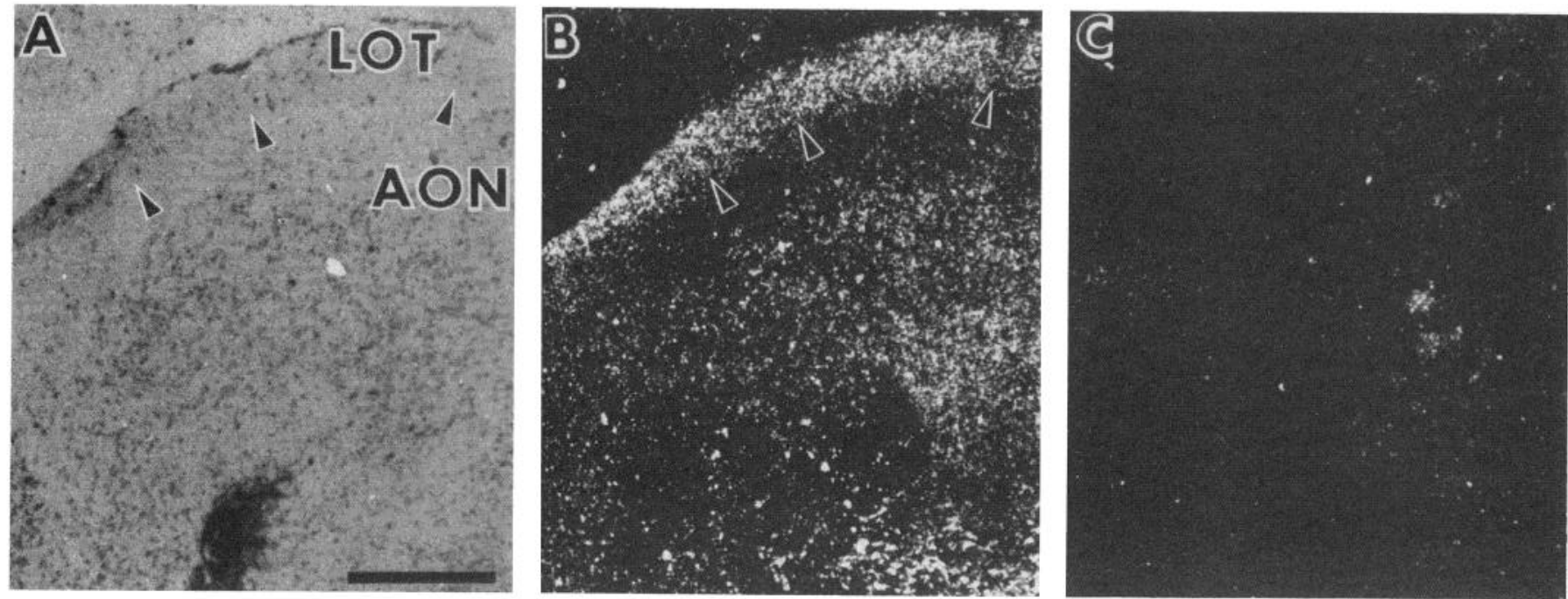

Figure 5. Distribution of CCK binding sites in the caudal guinea pig olfactory bulb. $A$, Brightfield photomicrograph of an autoradiogram of the dorsolateral quadrant of the olfactory bulb (coronal plane). $B$, Darkfield photomicrograph of the autoradiogram shown in $A$. $C$, Darkfield photomicrograph of an autoradiogram generated from a tissue section consecutive to the one shown in $A$ and incubated with $50 \mathrm{pm}\left[{ }^{125} \mathrm{I}\right] \mathrm{CCK}-33$ and $10^{-7} \mathrm{M}$ CCK-8 to produce an image of the nonspecific binding. The low density of grains over the area of the lateral olfactory tract $(L O T)$ suggests that the nonspecific binding was relatively low. The arrowheads indicate the transition area between the LOT and the plexiform layer of the anterior olfactory nucleus (AON). See the text for discussion. Bar $=490 \mu \mathrm{m}$.

phologically similar to the tufted cells described by Lohman (1963). The grain density over the inner granule cell layer (ICGL) of the accessory olfactory bulb was somewhat higher than the density over the ICGL of the main bulb. Within the ICGL, grains were found primarily in the neuropil, and, particularly in the case of the main bulb, the grain density was highest in the area subadjacent to the mitral cell layer.

The most striking finding in the caudal part of the olfactory bulb (Fig. 5) was the presence of a moderately high grain density over areas traversed by fibers of the olfactory tract. The grains were found superficially along the dorsal and lateral surface of the caudal olfactory bulb. The grain distribution in the caudal extension of the olfactory bulb was similar to that observed rostrally, although the density over the EPL was somewhat decreased near the olfactory peduncle.

Similar results were obtained in the rat olfactory bulb (Fig. 6), with the notable exception that the glomeruli contained high grain densities.

Retrobulbar area. CCK binding sites were found to have a lamellar distribution in which the highest density of sites was localized to the most superficial lamina of the peduncle. In order to describe this distribution more fully, some salient anatomical features of the region will first be summarized. The olfactory peduncle has been described as having a plexiform layer which overlies ventromedially the cells of the anterior olfactory nucleus (Herrick, 1924; Vaz Ferriera, 1951) and caudally and dorsolaterally the rostral extension of the prepyriform cortex (Ramon y Cajal, 1911; Lohman, 1963). Furthermore, in the most rostral divisions of the peduncle, the fibers of the olfactory tract circumferentially bound the peduncle (superficial to the plexiform layer). Caudally, the LOT fibers are found in a compact fiber bundle which indents the ventrolateral surface of the prepyriform lobe.
Fibers extend dorsolaterally and medially from this bundle to form a shell overlying the plexiform layer of the peduncle.

In sections through the rostral olfactory peduncle, a high density of autoradiographic grains overlies the surface of the peduncle circumferentially. Caudally, the distribution of grains changed slightly (Fig. 7). The superficial band of high grain density extended from the rhinal sulcus dorsolaterally to the level of the pars externa of the anterior olfactory nucleus (AON) ventrally. At this level of the neuraxis, the grain density was very low over the cells and adjacent plexiform layers of the pars externa (vide infra). Medial to the pars externa, the band of grains resumed with gradually increasing intensity and extended along the ventromedial surface of the hemisphere, superficial to the pars medialis of the AON. Both rostrally and caudally, the area of high density appeared to overlay the superficially situated LOT fibers and the external half of the plexiform layer. The inner half of the plexiform layer contained a low grain density.

In the caudal part of the olfactory peduncle, the ventrolaterally situated axial LOT bundle contained a very low grain density.

Certain subdivisions of the anterior olfactory nucleus exhibited significant $\left[{ }^{125} \mathrm{I}\right] \mathrm{CCK}-33$ binding. For example, moderate grain densities were found in the neuropil of the external, lateral, and dorsal subdivisions of the AON (rostrally). It was noted that an area of very low grain density separated the cells of the pars dorsalis from the portion of the peduncle traversed by fibers of the LOT (and containing a moderately high grain density). This area can be seen in Figure 5 and may correspond to part of the plexiform layer of the pars dorsalis. No comparable low density region was observed in the rostrolateral part of the peduncle where the LOT fibers lie adjacent to the cells of the external subnucleus. 

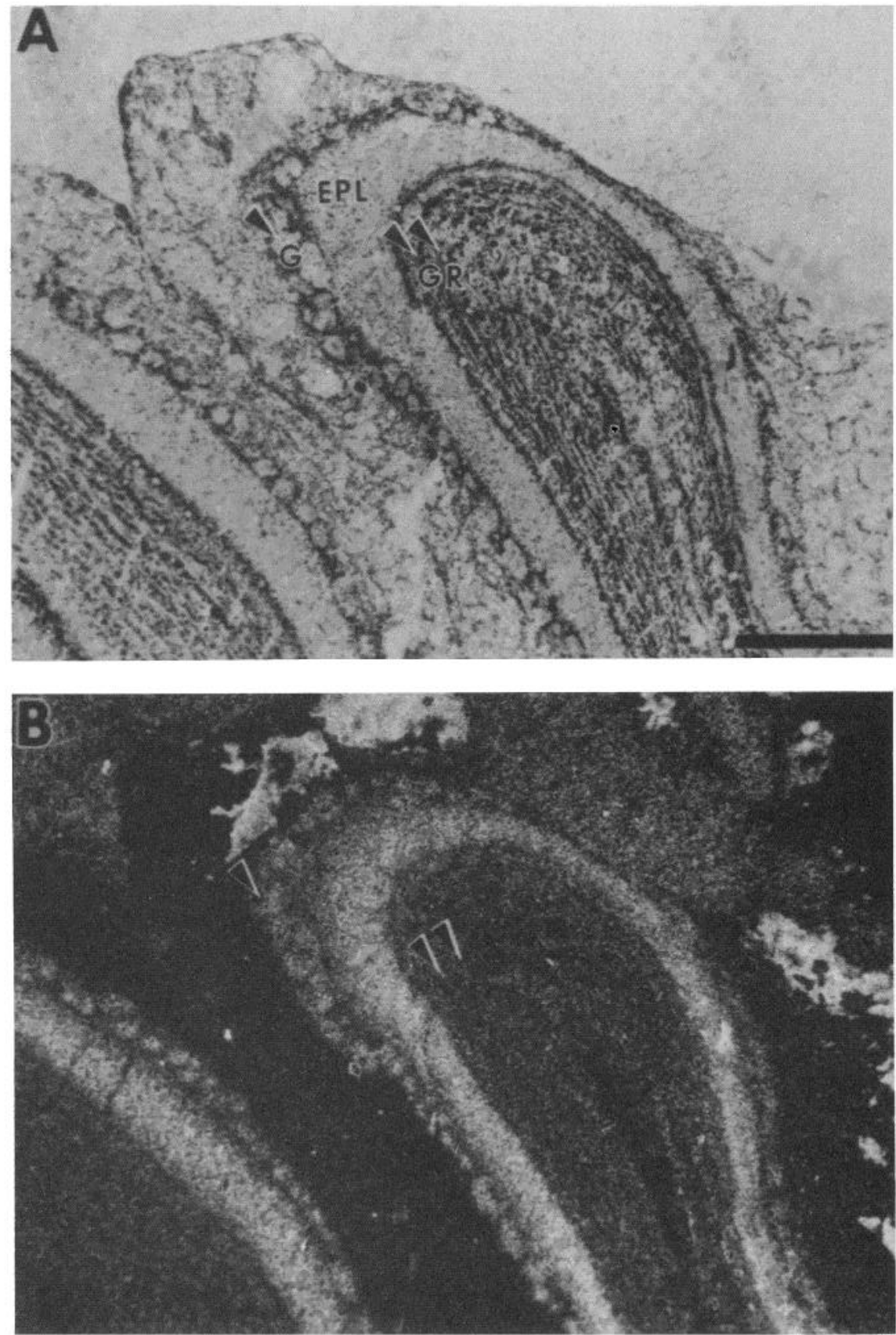

Figure 6. Distribution of CCK binding sites in the rat olfactory bulb. $A$, Brightfield photomicrograph of an autoradiogram at the level of the olfactory bulb (coronal plane). $B$, Darkfield photomicrograph of the autoradiogram shown in $A$. Note presence of grains in the glomerular layer $(G)$ which is indicated by the arrowhead on the left. The double arrowhead indicates the locus of the inner granule layer $(G R)$. $E P L$, external plexiform layer. See the text for discussion. Bar $=714 \mu \mathrm{m}$.

Caudally in the olfactory peduncle, the cells of the external and lateral subdivisions of the AON shift such that the lateral group is not bordered laterally by the external group (Johnson, 1959; Lohman, 1963). At this level, the pars externa was associated with a very low grain density, whereas the lateral subdivision was associated with a higher density than that found more rostrally.

A moderate grain density was observed throughout (i.e., over the cells and neuropil) the posterior and ventral subdivisions of AON.
Prepyriform cortex (Table III). Three distinct laminae were recognized: a cell-sparse superficial plexiform layer (I), an underlying pyramidal cell layer (II) containing small and medium-sized cells, and a deep polymorphic layer (III). Fiberarchitectonic studies of Flores (1911) have suggested a further division of lamina I into at least three regions: a superficial fibrillar layer $(I \propto)$ which contains LOT fibers, a deeper layer (IA) in which LOT fibers establish synaptic contacts with the distal dendrites of cells in deeper layers (Lohman, 1963; White, $1965 \mathrm{~b})$, and, in the deepest half of lamina I, a layer (IB) 
TABLE III

Distribution of CCK binding sites in guinea pig brain

See Table I for the correlation between absolute grain density and the relative density ratings $(1,2,3,4)$. The data are based on observations in three to five animals. The anatomical terminology is derived from references cited in the text. See the text for details.

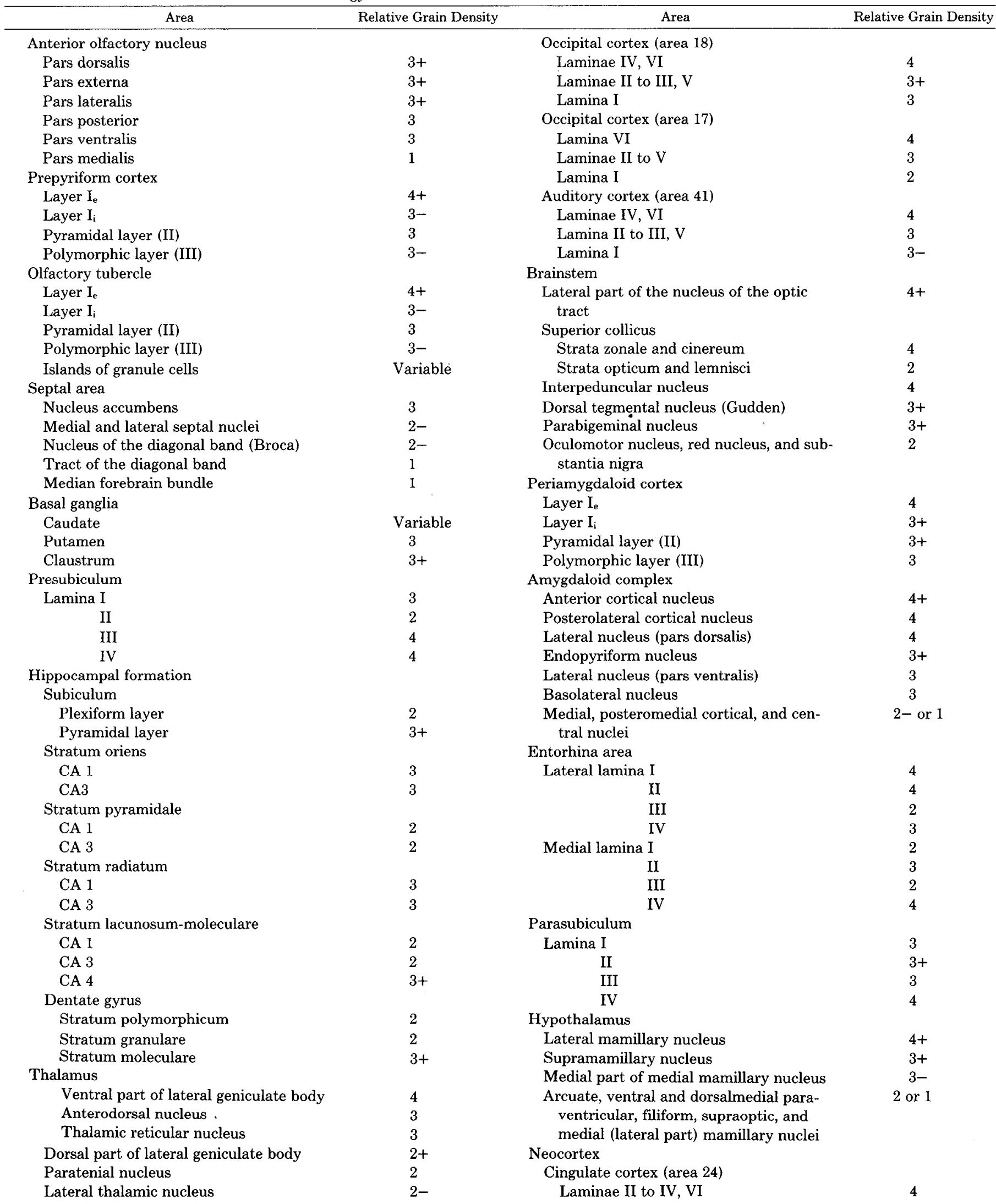


TABLE III-continued

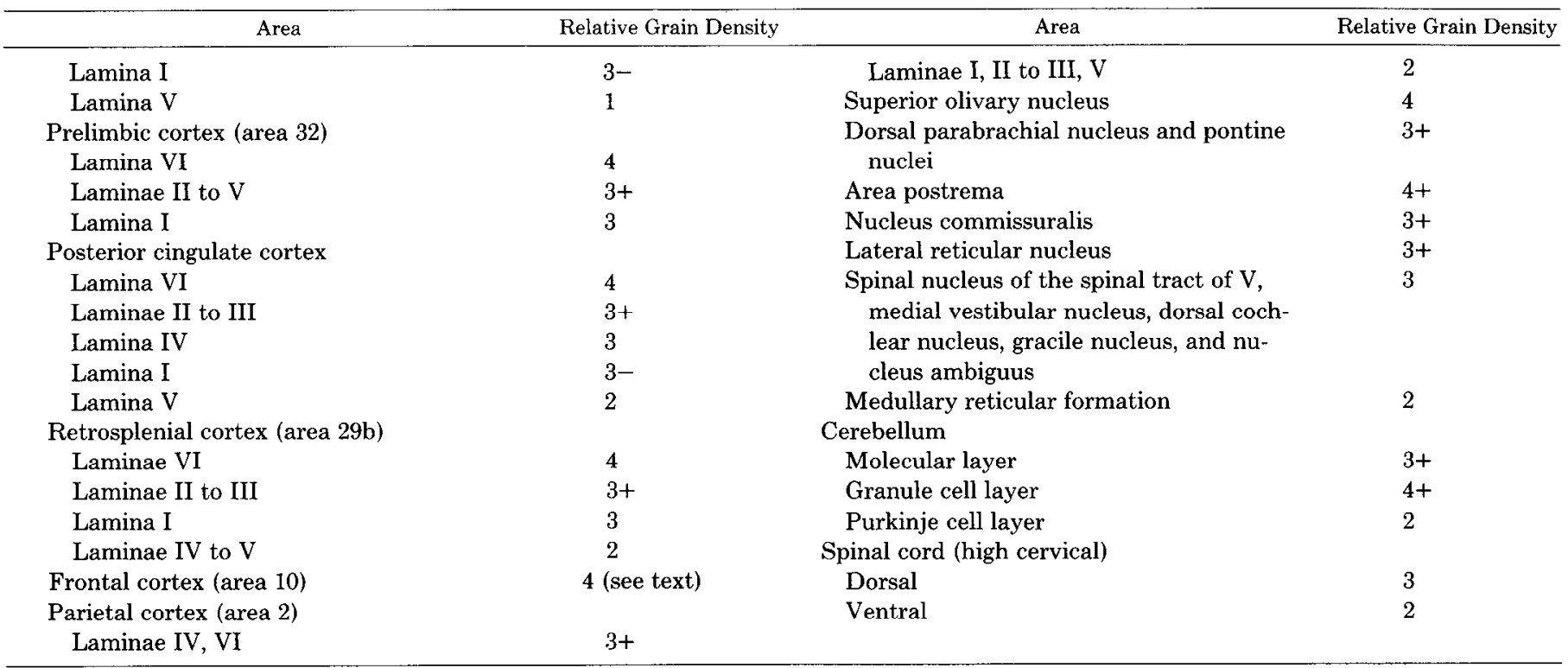

in which olfactory association and commissural fibers ramify (Heimer, 1968; Price, 1973). The pyronin Y stain used in this study did not allow ready determination of the foregoing subdivisions of I. For the purpose of this study, lamina I was, therefore, subdivided into superficial $\left(I_{e}\right)$ and deep $\left(I_{i}\right)$ strata, each of which occupies one-half the width of lamina $I$.

As in the olfactory peduncle, the grains were present in a superficial band of high density which extended from the rhinal sulcus to the ventromedial surface of the hemisphere (Fig. 7). This band overlies lamina $I_{e}$ (which presumably includes $\mathrm{I} \propto$ and IA). The density in this layer appeared to decrease slightly in the medial part of prepyriform cortex (particularly on the ventromedial face of the hemisphere). Furthermore, the density in $I_{e}$ decreased along a rostrocaudal gradient (being greatest rostrally). Lamina $\mathbf{I}_{\mathrm{i}}$ was associated with a uniform, lowmoderate grain density. Grains were found over the cells and in the neuropil of lamina II. The portions of laminae $I_{i}$ and II situated deep to the axial LOT bundle were associated with a higher grain density than the adjacent prepyriform cortex. Grains were also found in the neuropil of lamina III. Similar results were obtained in the rat (Figs. 8 and 9).

The band of high grain density extended into the depth of the rhinal fissure ventrally, where it was confined to the superficial half of the cell-sparse plexiform layer. The band also extended into the dorsal lip of the fissure, but the density decreased to a low level near the dorsal surface of the fissure.

Olfactory tubercle. Following Johnson (1959), three laminae in the guinea pig olfactory tubercle were recognized: a superficial plexiform layer (I), a pyramidal layer (II) containing small and medium-sized cells, and a deep polymorphic layer (III). Lamina I was subdivided into superficial $\left(\mathrm{I}_{\mathrm{e}}\right)$ and deep $\left(\mathrm{I}_{\mathrm{i}}\right)$ halves as explained above.

As in the prepyriform area, the band of high density in lamina $I_{e}$ decreased along a rostrocaudal gradient. Autoradiographic grains were present in the neuropil of the granule cell islands contained within lamina I (Lohman, 1963). A moderately high grain density was found in the caudal group of islands (situated adjacent to the nucleus accumbens); a moderate density was observed over the rostromedial group, and a low density was present over the rostrolateral group. The grain density in laminae II and III was similar to that in lamina $\mathbf{I}_{\mathrm{i}}$.

The anterior limb of the anterior commissure contained a very low grain density.

Similar results were obtained in the rat (Figs. 8 and 9) with the following exceptions. Caudally, the band of grains in lamina $I_{e}$ decreased along a lateromedial gradient which seemed more pronounced than in the guinea pig. In addition, lamina III contained a rather high grain density which also decreased along a lateromedial gradient. Finally, only a negligible grain density was found over the islands of Calleja.

Septal area. In general, the septal area contained a very low density of autoradiographic grains. 'The nucleus accumbens, an exception, contained a moderate density.

Similar results were obtained in the rat with the exception that the medial part of the nucleus accumbens contained a high density of grains whereas the lateral part contained a moderate density (Figs. 8 and 9).

Basal ganglia. The distribution of CCK binding sites in the caudate appeared to be nonuniform.

In the rat, a high grain density overlay the dorsomedial part of the caudate-putamen and a lower density overlay the ventrolateral part (Fig. 9).

Amygdaloid region. The anatomical distribution of the binding sites was analyzed with the aid of the cytoarchitectonic descriptions of Kretteck and Price (1978a) and Hall and Geneser-Jensen (1971). Following Hall and Geneser-Jensen, the cortical amygdaloid nucleus was subdivided into anterior (CA), posterolateral (CL), and posteromedial (CM) areas, and the lateral amygdaloid nucleus was subdivided into a dorsal (D) and a ventral area.

In accord with rationale presented in the analysis of the prepyriform cortex, three strata were recognized in the periamygdaloid cortex: a superficial, cell-sparse plexiform layer-which was divided into an inner $\left(\mathrm{I}_{\mathrm{i}}\right)$ and outer $\left(\mathrm{I}_{\mathrm{e}}\right)$ half-a subadjacent pyramidal layer (II), and 

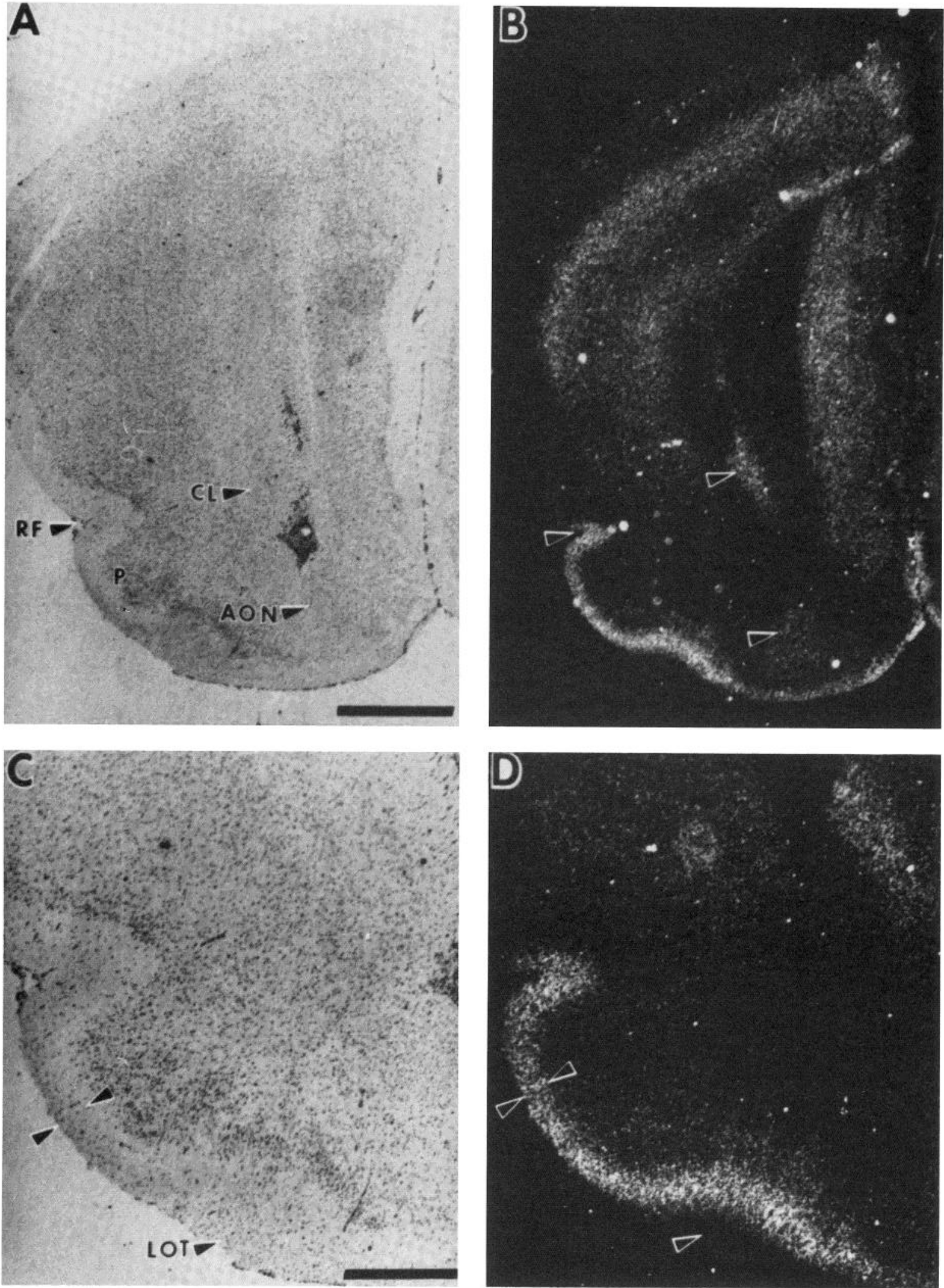

Figure 7. Distribution of CCK binding sites in the guinea pig forebrain at the level of the olfactory peduncle. $A$, Brightfield photomicrograph of an autoradiogram of the guinea pig forebrain (coronal plane). Bar $=1540 \mu \mathrm{m} . B$, Darkfield photomicrograph of the autoradiogram shown in $A$. The arrowheads indicate the location of the rhinal fissure $(R F)$, claustrum $(C L)$, and anterior olfactory nucleus $(A O N)$. $C$, Higher magnification photomicrograph of the autoradiogram shown in $A$. Bar $=770 \mu \mathrm{m} . D$, Darkfield photomicrograph of the close-up shown in $C$. The opposing arrowheads demarcate the boundaries of lamina Ie. The single arrowhead identifies the lateral olfactory tract $(L O T)$. $P$, prepyriform cortex. See the text for discussion. 

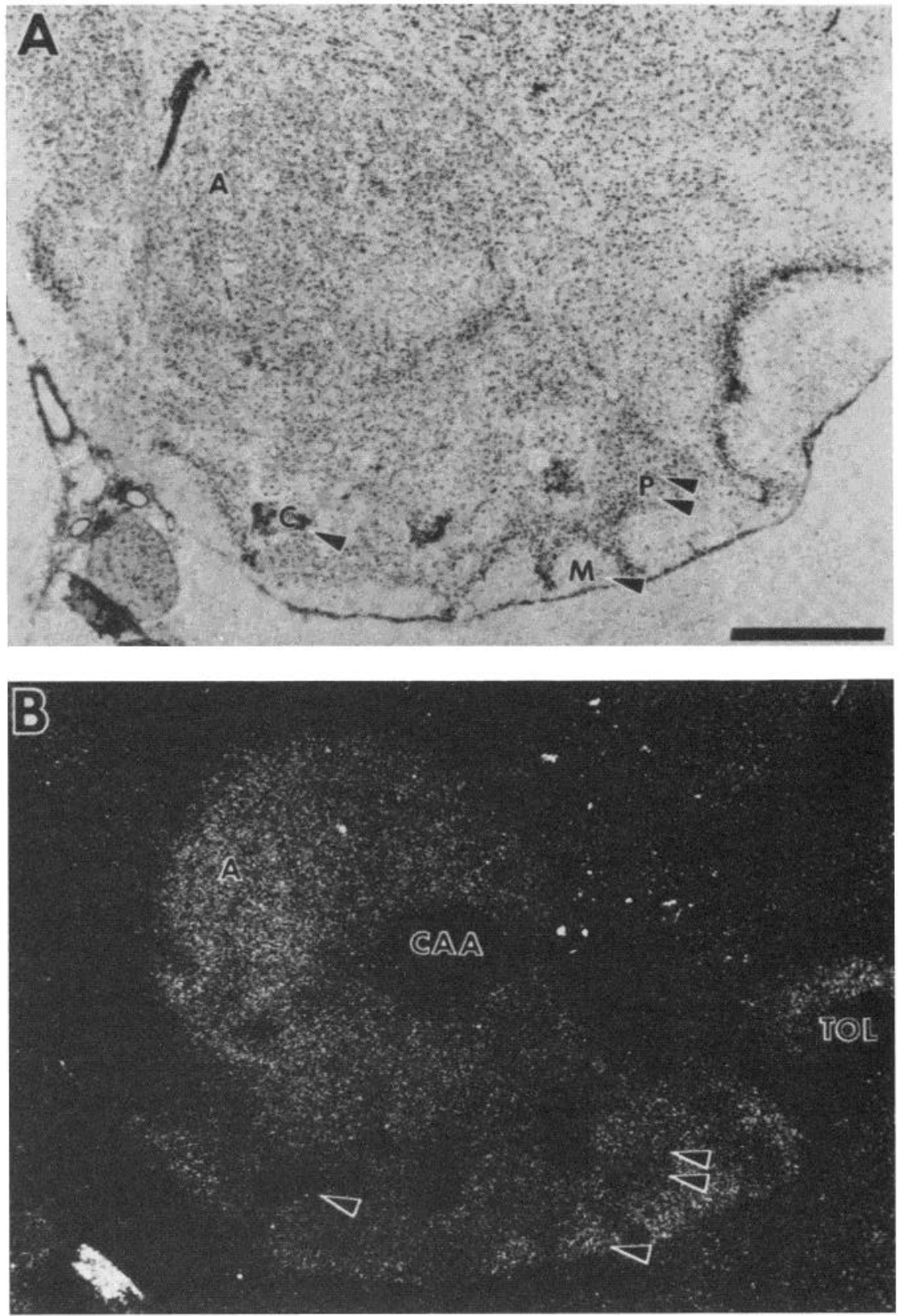

Figure 8. Distribution of CCK binding sites in the rat olfactory tubercle. A, Brightfield photomicrograph of an autoradiogram of the rat forebrain (coronal plane). B, Darkfield photomicrograph of the autoradiogram shown in $A$. The arrowheads indicate the location of various anatomical structures. $A$, nucleus accumbens; $C$, island of Calleja; $C A A$, anterior limb of the anterior commissure; $M$, molecular layer of the olfactory tubercle; $P$, pyramidal cell layer of the olfactory tubercle; $T O L$, lateral olfactory tract. See the text for discussion. Bar $=800 \mu \mathrm{m}$.

a deep polymorphic layer (III). The grains in laminae II and III were found primarily in the neuropil.

The highest densities of CCK binding sites in the amygdaloid complex were found in CA, CL, and D (Figs. 10 and 11; Table III). In CA, a very high density overlay the superficial half of the plexiform layer. A moderate density was found over the inner half of the layer, over the subadjacent pyramidal layer (in the neuropil and over the long processes of pyramidal cells), and over the polymorphic layer (in the neuropil). The distribution of grains in CL was similar to that in CA: a high density overlay the superficial half of the plexiform layer; a moderate density was found over the inner half of the plexiform layer and in the neuropil of the underlying cellular layer. As was observed in the prepyriform area, the grain density in CL decreased along a rostrocaudal gradient.

A particularly low density of grains was observed over the medial and central amygdaloid nuclei. The central nucleus was bordered dorsomedially and ventromedially by a band of moderate grain density. The grains were located in the neuropil just deep to the fibers of the stria terminalis. The band appeared to be continuous with the grains over the inferior putamen. 

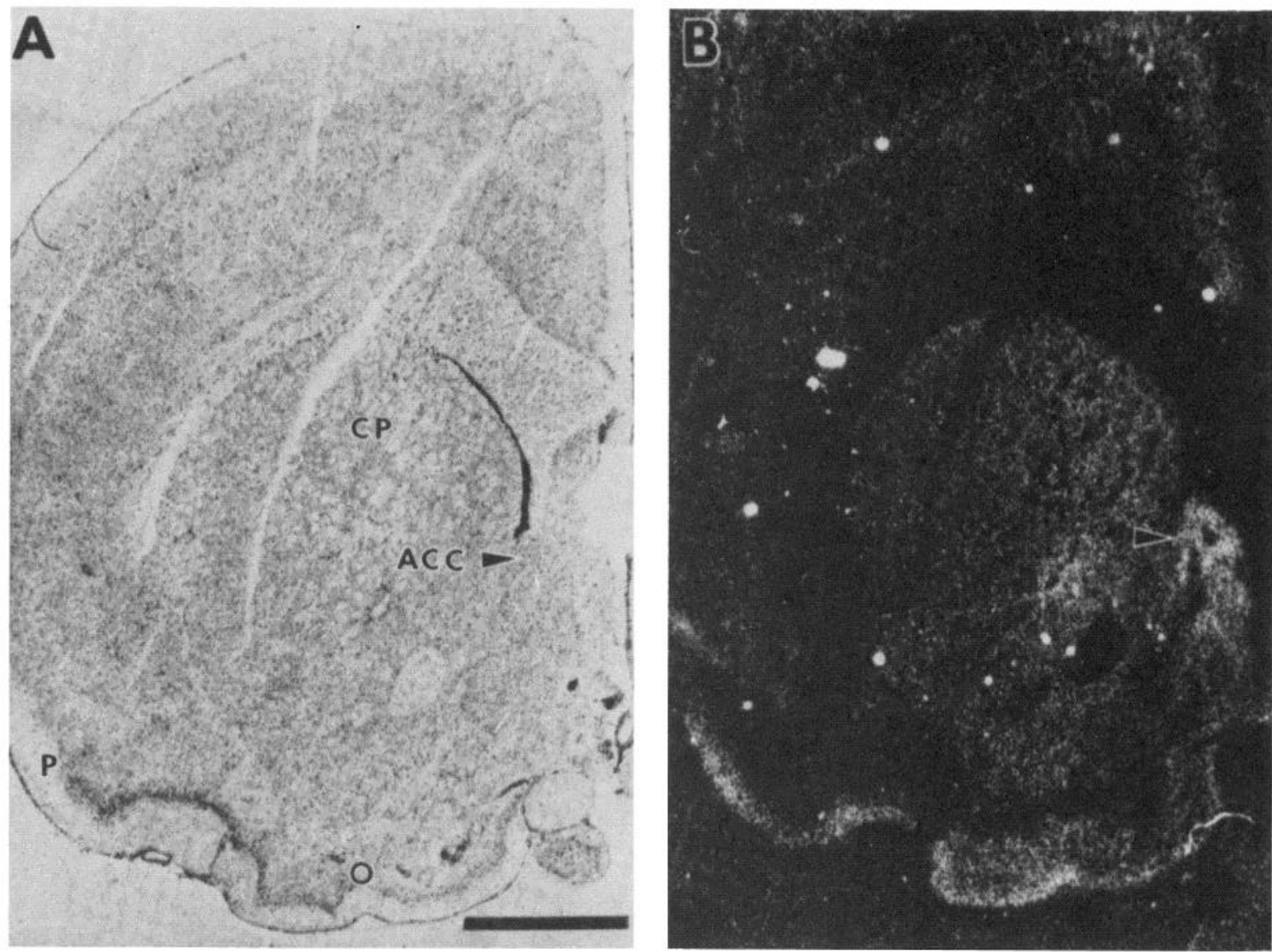

Figure 9. Distribution of CCK binding sites in the rat brain at the level of the prepyriform cortex $(P) . A, B r i g h t f i e l d$ photomicrograph of an autoradiogram of the rat forebrain (coronal plane). $B$, Darkfield photomicrograph of the autoradiogram shown in $A$. The arrowhead marks the locus of the medial nucleus accumbens. $A C C$, nucleus accumbens; $C P$, caudate-putamen; $O$, olfactory tubercle. See the text for discussion. Bar $=893 \mu \mathrm{m}$.

Entorhinal cortex and parahippocampal formation. The cytoarchitectonic descriptions of Blackstad (1956) and Lorente de No (1934) were utilized in the analysis of these regions. Following Geneser-Jensen and Blackstad (1971), the entorhinal area was subdivided into medial and lateral parts. Laminae IV to VI of the entorhinal cortex and of the pre- and parasubmiculum have been recognized as a single lamina (IV) in this study.

Although the medial and lateral entorhinal areas contained high grain densities, the distribution of grains within these areas was markedly different (Fig. 12; Table III). In the lateral entorhinal area, most of the grains were in the superficial laminae (Fig. $12, A, B, E$, and $F$ ). The opposite was true in the medial entorhinal area (Fig. $12, A, B, E, F, G$, and $H$ ).

Lamina I of the lateral entorhinal area contained a high grain density in its outer one-third. A lower density was present over the inner two-thirds of lamina I. The cell islands of lamina II (characteristic of lateral entorhinal cortex) contained grains over the cells and in the neuropil. The neuropil between the islands (extending from the ventral surface of the brain to the deep border of lamina II), however, was associated with a low grain density (Fig. 12, $C$ and $D$ ). The moderate grain density over lamina IV increased to a high level dorsolaterally. As Kretteck and Price (1977) point out, the deeper layers of the dorsal lateral entorhinal cortex are continuous with the endopyriform nucleus, an area of moderately high grain density (vide supra). A low-moderate grain density was observed over the white matter subadjacent to lamina IV.

In lamina IV of the medial entorhinal area, grains were found in the neuropil and over some of the large cells. The high grain density of lamina IV extended into the subadjacent white matter of the angular bundle. The density in the angular bundle decreased along a ventrodorsal gradient, assuming a low-moderate level approximately $1 \mathrm{~mm}$ dorsal to lamina IV. As in the lateral entorhinal region, the lamina dissecans (which is included in lamina III) of M. Rose (1912) contained a low grain density, as did the superficial pyramidal cells of lamina III. In the medial entorhinal area of the rat, a moderately high grain density was present in the outer half of lamina I and lamina III (including the lamina dissecans).

Following Geneser-Jensen and Blackstad (1971), the deep laminae of the parasubiculum were regarded as continuous with those of the medial entorhinal region. Thus, the high density of grains in lamina IV of the parasubiculum formed a band which appeared to be continuous with that over lamina IV of the medial entorhinal area (Fig. 12, E, F, G, and $H$ ). The cell poor region superficial to this band appeared to be continuous with the lamina dissecans of the medial entorhinal area. In the parasubiculum, however, this region was associated 

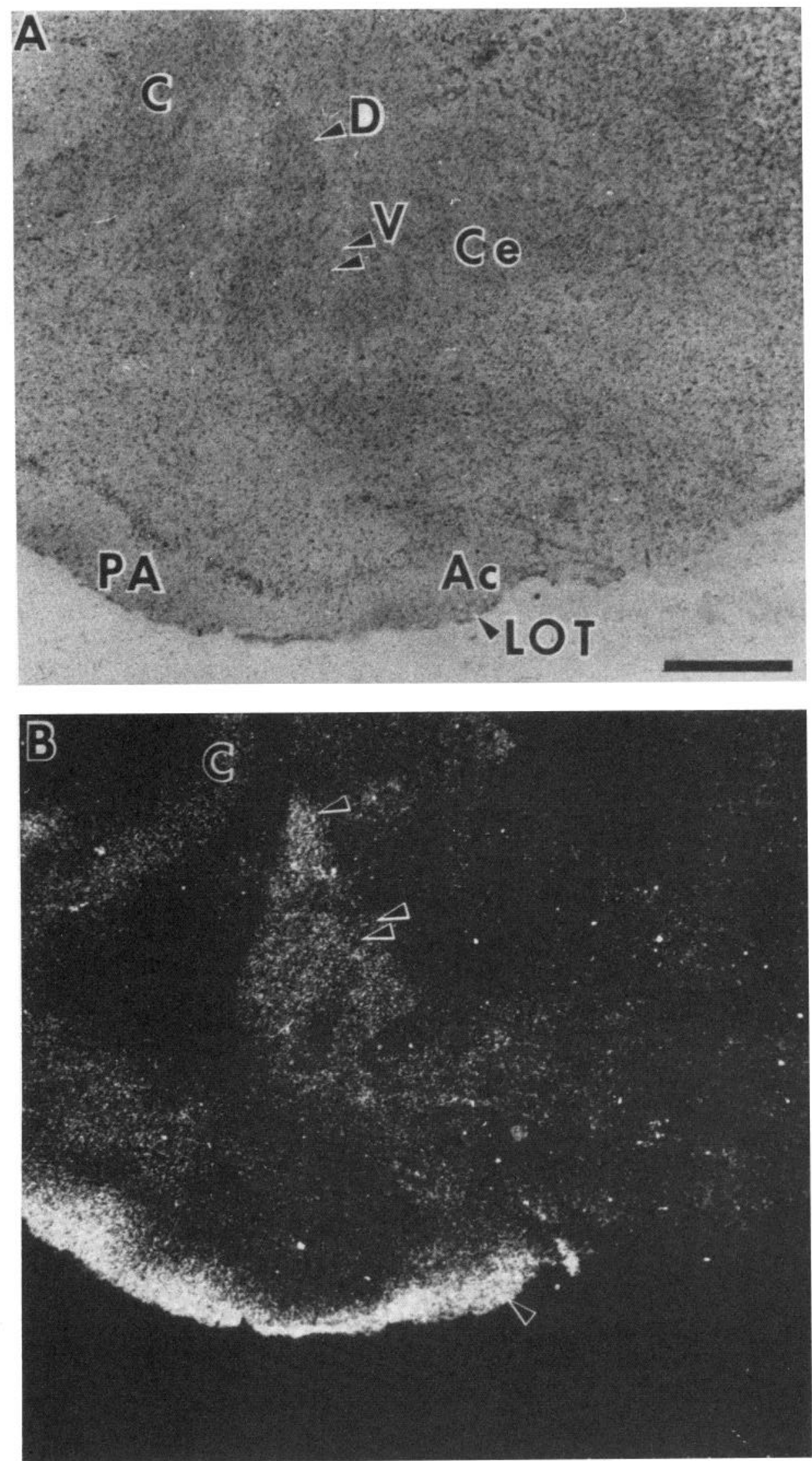

Figure 10. Distribution of CCK binding sites in the guinea pig at the level of the amygdala. A, Brightfield photomicrograph of an autoradiogram at the level of the amygdala (coronal plane). $B$, Darkfield photomicrograph of the autoradiogram shown in $A$. The single arrowhead near $D$ indicates the dorsal part of the lateral amygdaloid nucleus, and the double arrowhead indicates the ventral part of the lateral nucleus. $A c$, anterior cortical nucleus of the amygdala; $C$, claustrum; $C e$, central amygdaloid nucleus; $D$, dorsolateral amygdaloid nucleus; $L O T$, lateral olfactory tract; $P A$, periamygdaloid cortex; $V$, ventrolateral amygdaloid nucleus. See the text for discussion. Bar $=597 \mu \mathrm{m}$. 


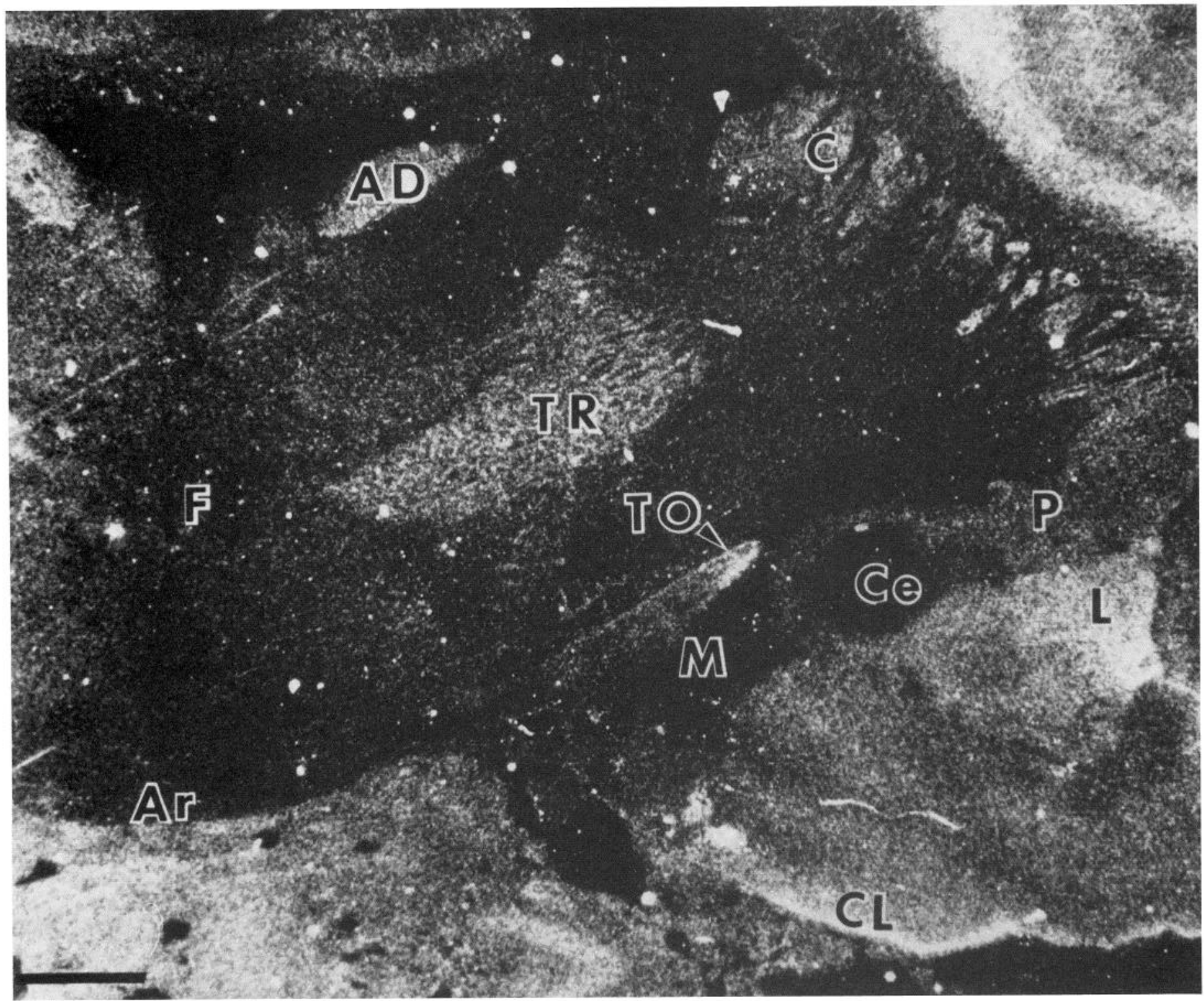

Figure 11. Distribution of CCK binding sites in the guinea pig at the level of the thalamus. Darkfield photomicrograph of an autoradiogram of the guinea pig thalamus, hypothalamus, and amygdala (coronal plane). $A D$, anterodorsal nucleus of the thalamus; $A r$, arcuate nucleus; $C$, caudate nucleus; $C e$, central amygdaloid nucleus; $C L$, posterolateral cortical nucleus; $F$, filiform nucleus; $L$, lateral amygdaloid nucleus; $M$, medial amygdaloid nucleus; $P$, putamen; $T O$, optic tract; $T R$, thalamic reticular nucleus. Bar $=1290 \mu \mathrm{m}$.

with a moderate grain density (versus a low density in the entorhinal area). The grains over lamina II of the parasubiculum were found mainly in the neuropil.

The density of binding sites in the presubiculum was greatest in the caudal part of the region. The band of high grain density in lamina IV appeared to be continuous with that extending across the parasubiculum and the medial entorhinal cortex. Within laminae III and IV, most of the grains were found in the neuropil. The distribution of grains in the plexiform layer (I) was nonuniform: a moderate density was found over the outer half and a lower density was found over the inner half.

In the postsubiculum, a moderately high grain density was observed in lamina VI.

Hippocampal formation. The cytoarchitectonic descriptions of Ramon y Cajal (1911) and Lorente de No
(1934) were utilized for analysis of this region. Blackstad's (1956) terminology has been adopted. In general, the hippocampal CKK binding sites were confined to discrete laminae and exhibited graded density changes along dorsoventral and mediolateral axes (Figs. 12 and 13).

In the ventral subiculum, grains were distributed along a dorsoventral gradient (Fig. 12, $E, F$, and $H$ ). Adjacent to area CA1, the grain density was high, whereas in the region adjacent to the presubiculum the density was significantly lower. Thus, the grains may be concentrated in laminae II to IV (over cells and in the neuropil) of Lorente de No's prosubiculum (1934). The subadjacent angular bundle contained a moderate grain density.

In the subicular-CA1 transition area, the laminar distribution was as follows (Fig. $12, A$ and $B$ ). The grain density over the deep part of the plexiform layer was 
greater than that found in the subiculum. Moreover, these grains formed the ventral extreme of a band which extended dorsally into the stratum radiatum of CA1. The grain density over the superficial pyramidal cells was less than that found in the subiculum and, dorsally, was of the same low level found over the pyramidal layer of CA1.

Areas CA1 and CA3 were similar with regard to their lamellar distribution of binding sites but were slightly different with regard to intralamellar grain density changes along a mediolateral axis (Figs. 12, $A$ and $B$ and $13)$. In the stratum radiatum of $\mathrm{CA} 1$ and $\mathrm{CA} 3$, most of the grains were confined to the outer two-thirds of the lamina. In field CA3, a distinction between the deep part of the stratum radiatum and the stratum lucidum of Honneger could not be made with the pyronin Y stain, but the low density area in the stratum radiatum of CA3 probably corresponds, at least partially, to the stratum lucidum. The grains formed a band which, in each case, extended across much of the sector. Moreover, the grain density of the band decreased in a mediolateral direction in both CA1 and CA3 (as seen in coronal sections such as Fig. 13). Although grains occupied the entire width of the stratum oriens of both CA1 and CA3, the distribution of the grains along the mediolateral axis was different in the two regions. In CA1, the grain density decreased along a steep mediolateral gradient. The grains in the stratum oriens formed a band which extended from the subiculum through the adjacent third (approximately) of CA1, a point beyond which the density in the stratum radiatum was still elevated. In $\mathrm{CA} 3$, however, the gradient of density change was the same in the stratum radiatum and in the stratum oriens. Thus, the density was greatest near the hilus of the dentate gyrus and decreased to a low level at the laterally situated (in coronal sections at the level of Fig. 13) bend in the stratum pyramidale which marks the transition between areas CA1 and CA3.

In CA4 (Fig. 13), the grain density was somewhat higher near the polymorphic layer of the dentate gyrus, particularly in the transition zone between CA4 and CA3. The grains were found primarily in the neuropil, although grains were also seen over the somata of some of the larger pyramidal cells.

Within the molecular layer of the dentate gyrus, the distribution of grains was nonuniform: graded changes were observed along rostrocaudal and dorsoventral axes. In coronal sections through lemporal (i.e., caudolateral) regions of the hippocampus, the following results were obtained (Fig. 12, $A$ and $B$ ). Ventrally, the grain density was highest in the outer half of the molecular layer and lowest in the inner half of the lamina. At a mid-dorsoventral level, the grains were more clearly confined to the outer half of the molecular layer. Dorsally, the distribution changed qualitatively: the inner quarter of the molecular layer contained more grains than the outer three-quarters. The gradient was not as sharply defined as at the mid-dorsoventral level. In coronal sections through the septal (i.e., rostrodorsal) hippocampus (Fig. 13 ), the following grain distribution was observed. The density over the outer blade's (Swanson et al., 1978) molecular layer was uniformly high. In the inner blade, however, the grain density was highest over the inner quarter of the molecular layer and lowest in the superficial part of the lamina. In the granular and polymorphic layers of the dentate gyrus, the grain density was low in all levels which were examined.

The rat and guinea pig differed in some respects with regard to the grain distribution in the hippocampal and entorhinal areas. Area CA4 and the stratum lacunosummoleculare, in the rat, contained the highest grain density in the hippocampus. In the medial entorhinal area, lamina III and the superficial part of lamina I had the highest grain densities. The distribution of grains in the presubiculum and retrosplenial cortex appeared to be the same in the rat and guinea pig.

Neocortex. To determine the anatomical distribution of binding sites in the cerebral cortex, the cytoarchitectonic studies of Krieg (1946a, b), J. Rose and Woolsey (1948), and M. Rose (1927) were consulted. Krieg's terminology will be used in the following description unless otherwise noted. In general, the cerebral cortex contained a high density of CCK binding sites. The binding sites were not uniformly distributed among the various cortical regions nor within a given region. A common finding among the various areas studied, however, was that lamina IV contained a high density of sites whereas lamina I contained a low density (area 10 is an exception to this rule). The limbic, retrosplenial, frontal, parietal, occipital, and auditory regions are described below.

A high density of grains was present in the cingulate cortex throughout its rostrocaudal extent. Most of the grains in laminae II to IV and VI were in the neuropil, although grains were also found over somata in lamina VI. The density in lamina $\mathrm{V}$ seemed to be lower in cingulate cortex than in any of the other cortical areas examined. The distribution of grains in lamina I was nonuniform. Anteriorly (Fig. 14), most of the grains in lamina I appeared to be confined to its outer third. The grains were thus situated in the location of the longitudinal external fiber stratum which extends from the hippocampus to the cingulate cortex. Similar results were oblained in the anterior cingulate cortex of the rat (Fig. 15). Furthermore, laminae II to IV appeared to be the locus of the highest density of cortical binding sites in the rat. This was not true for the guinea pig. Posteriorly, the distribution of grains was similar. The grains in lamina I, for example, were again superficially localized (Fig. 16).

In contrast to area 24 , the anterodorsal or prelimbic area (32) contained a moderately high, rather uniform grain density in laminae II to VI, with lamina VI containing the highest grain density. In these strata, the grains were found primarily in the neuropil. As in area 24 , a moderate density overlay the superficial part of lamina I (the probable locus of the longitudinal fiber bundle mentioned above), whereas a low density was present more deeply. Similar results were obtained in the rat.

The retrosplenial cortex (area 29b) also contained a high density of binding sites (Fig. 16). The grains in laminae I, II, and VI were found in the neuropil, although some somata in lamina VI contained grains. As was observed in the structurally similar cingular areas, a 

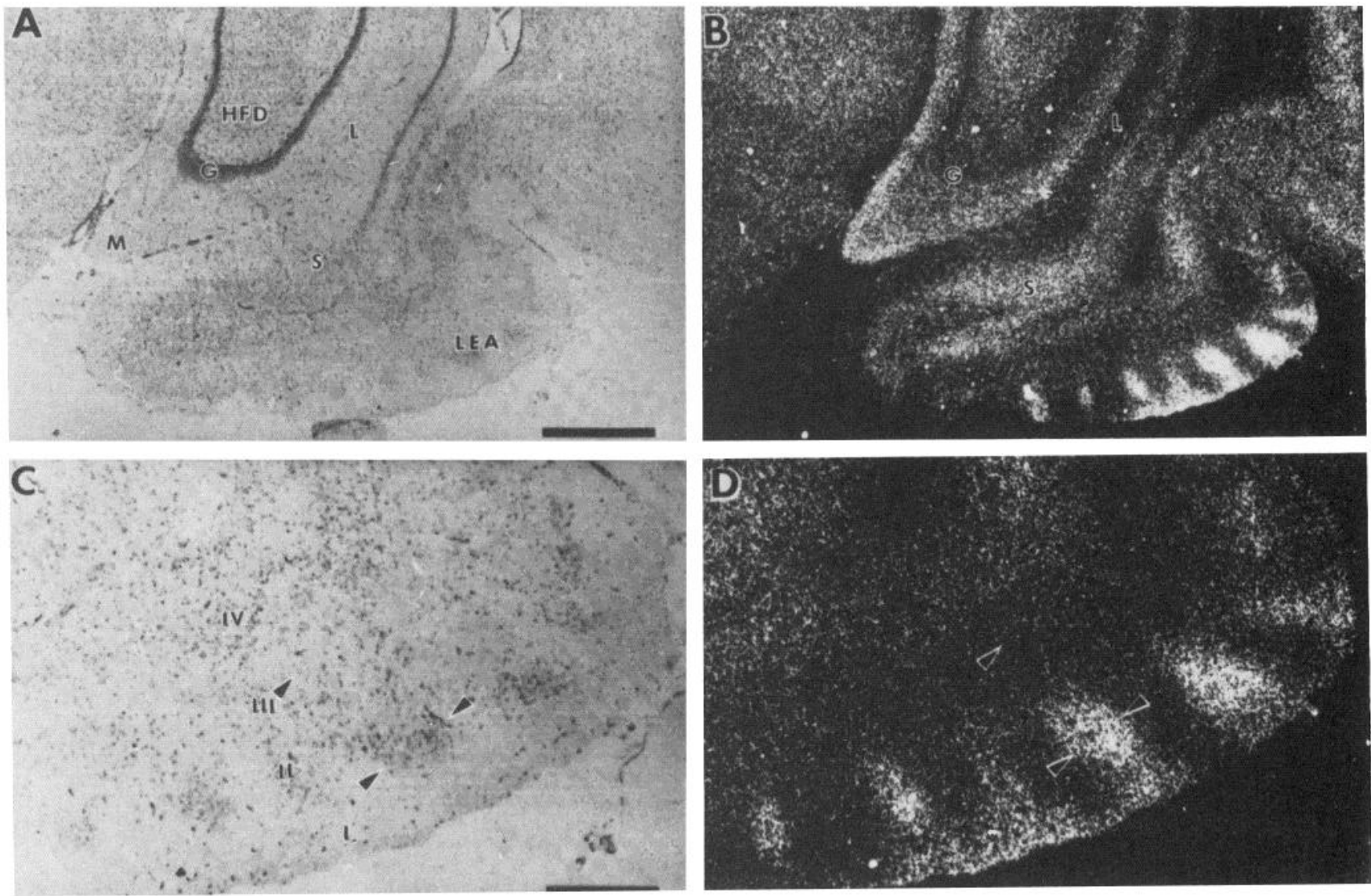

Figure 12. Distribution of CCK binding sites in the guinea pig entorhinal and hippocampal areas. $A$, Brightfield photomicrograph of an autoradiogram of entorhinal area and the ventral hippocampal area (coronal plane). Bar equals $1143 \mu \mathrm{m}$. $B$, Darkfield photomicrograph of $A$. $C$, Higher magnification photo of the lateral entorhinal area shown in $A$. Bar $=446 \mu$ m. Laminae $I, I I, I I I$, and $I V$ are indicated. $D$, Darkfield of $C$. Opposing arrowheads demarcate the borders of the cell islands in the lateral entorhinal cortex. The single arrowhead indicates the location of lamina II of the lateral entorhinal area. $E$, Brightfield photomicrograph of an autoradiogram of the entorhinal area caudal to the level of $A$ (coronal plane). Bar equals $746 \mu \mathrm{m}$. $F$, Darkfield photomicrograph of $E$. The arrowheads mark the boundaries between the presubiculum $(P)$, parasubiculum $(P A)$, medial entorhinal area $(M E A)$, and lateral entorhinal area $(L E A)$. $G$, Brightfield photomicrograph of the parahippocampal and entorhinal areas caudal to the level of $E$ (coronal plane). Bar $=955 \mu \mathrm{m}$. $H$, Darkfield photomicrograph of $G$. The double arrowheads mark the boundaries of $P, P A$, and $M E A$. The single unlabeled arrowheads demarcate the boundary between laminae III and IV of P, PA, and MEA. $A$, angular bundle; $G$, granule cell layer of the dentate gyrus; $H F D$, hilus fasciae dentatae; $L$, lamina lacunosum-moleculare of the hippocampus; $M$, molecular layer of the dentate gyrus; $R F$, rhinal fissue; $S$, subiculum.

moderate grain density overlay the outer third of lamina I, and a low density overlay the inner two-thirds. The area of moderate density in lamina I probably corresponds to the location of the longitudinal fibrous stratum present in this area and identical to that found in area 24 . In the rat, an area of high grain density extended through laminae II to VI. A moderate density was present elsewhere.

It was difficult to unambiguously identify the domains of individual cortical laminae (Fig. 7) in frontal cortex (area 10). The superficial laminae (probably corresponding to I to III) contained a moderate grain density, and the deep laminae (probably corresponding to IV to VI and possibly including the deep part of III) contained a high density. Within the deep laminae, the density seemed somewhat higher in the superficial (IV ?) and deep (VI ?) regions than in the central area (V ?).

In laminae IV and VI of the parietal region (area 2), the grains were found primarily in the neuropil (Fig. 17).
The laminar distribution of grains in cingulate and occipital cortex differed, especially in area 17, with regard to the grain density in lamina V (Fig. 17). Although the density was very low in cingulate cortex, the density was moderate in occipital cortex. Furthermore, areas 17 and 18 seemed to have slightly different grain distributions, because in area 18 two bands of high grain density were clearly distinguishable (mainly overlying laminae IV and VI), whereas in area 17 the grains appeared uniformly distributed throughout laminae II to V. Moreover, in area 18 , the grain density was moderate in the outer half of lamina I and low in the deep half, whereas in area 17, the density was uniformly low in this lamina.

Auditory cortex (area 41) was also found to contain a high density of binding sites in lamina VI and in an area which probably corresponds to lamina IV (Fig. 17).

Thalamus and hypothalamus. Only a few regions in the diencephalon contained significant densities of CCK binding sites (Table III; Figs. 11, 18, and 19). 

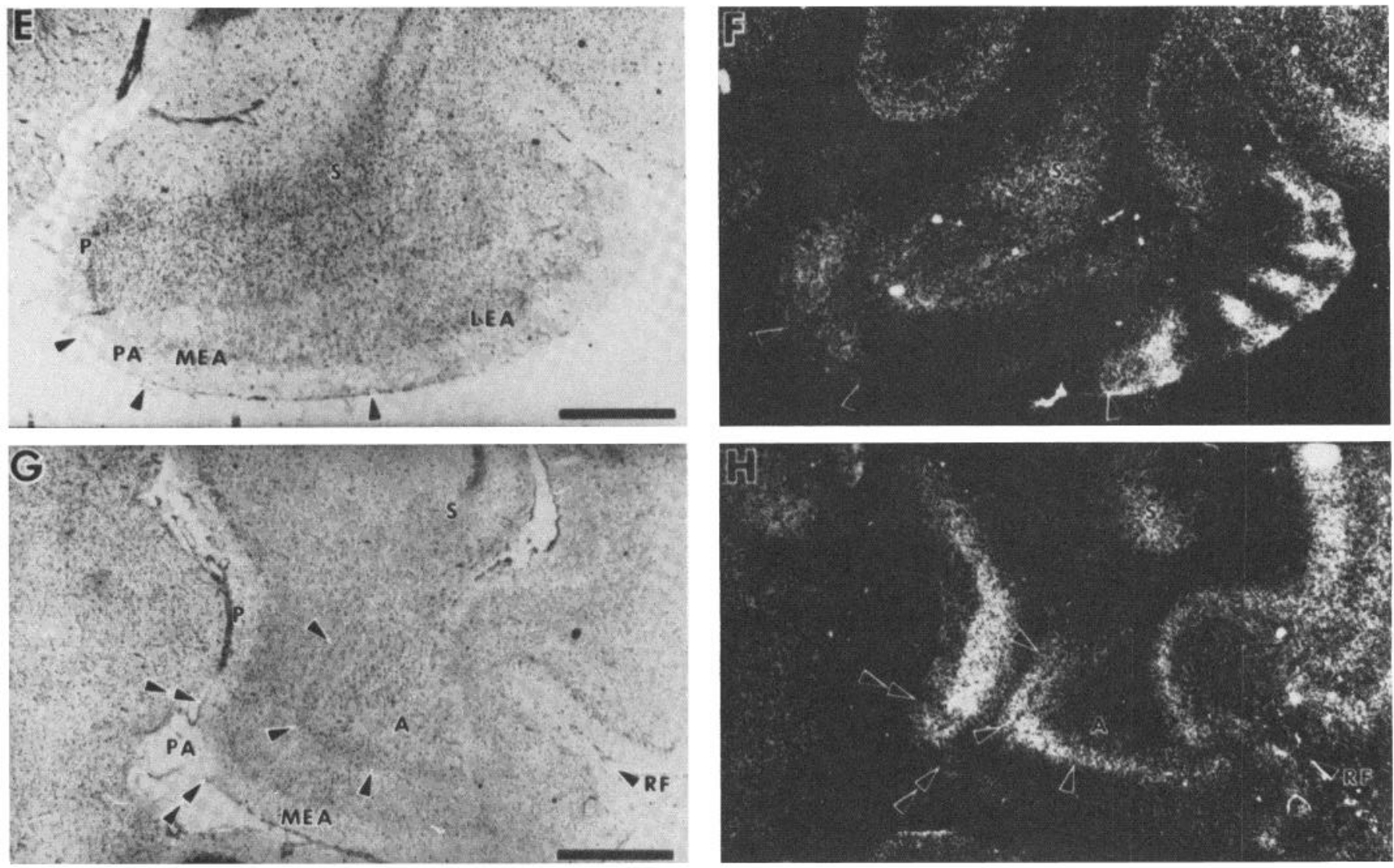

Figure 12-continued

The ventral part of the lateral geniculate body contained the highest grain density in the thalamus (primarily in the neuropil) and one of the highest grain densities in the guinea pig brain. The anterodorsal and thalamic reticular nuclei also contained significant grain densities. In the latter two areas, the grains were found primarily in the neuropil, although some were present over a few of the somata in the anterodorsal nucleus.

The lateral mamillary nucleus contained the highest grain density in the hypothalamus and was among the areas most enriched in CCK binding sites in the guinea pig brain. Within the nucleus, the grains were not uniformly distributed: the ventral quarter contained most of the grains (over the somata and their processes), and the remaining three-quarters contained a much lower grain density (over somata and in the neuropil).

Brainstem and cerebellum. Relatively few brainstem areas contained significant densities of autoradiographic grains. The cerebellum, on the other hand, contained a very high density of binding sites (Table III; Figs. 17 and 19 to 22 ).

The pretectal area contained one of the highest densities of CCK binding sites in the guinea pig brain (Fig. 17). Specifically, the lateral part of the nucleus of the optic tract contained a very high grain density in the neuropil and over the somata of very large, pyramidshaped cells (Fig. 20). A moderate grain density overlay the fibers of the optic tract which course along the dorsal aspect of the mesencephalon and penetrate the nucleus. Furthermore, in all the material analyzed for this study, a moderately high density of grains was present over the dorsolateral aspect of the optic tract (Fig. 11). A low density was present over the ventromedial part of the tract. These data are compatible with the notion that some of the pretectal CCK binding sites are associated with fibers of the optic tract, i.e., they are presynaptic binding sites. This possibility has been confirmed in preliminary enucleation experiments (M. A. Zarbin, manuscript in preparation). Another region associated with the visual system and found to contain a high density of binding sites was the superior colliculus (Fig. 16). Here, most of the grains were confined to the superficial strata receiving input from the occipital cortex. The interpeduncular nucleus also contained a high density of grains (Fig. 17). The grains appeared to be localized to various subdivisions of the nucleus, e.g., to the lateral and median subnuclei. Within the parabigeminal nucleus (otherwise known as the ventral rostral nucleus of the lateral lemniscus), the grains were confined mainly to the neuropil.

The cerebellum contained one of the highest grain densities in the guinea pig brain (Fig. 21). Neither the density nor the distribution of the grains appeared to vary among the different lobules. Within a given lobule, a very high grain density was present throughout the granule cell layer. A lower density overlay the neuropil of the molecular layer, and a very low density was present 

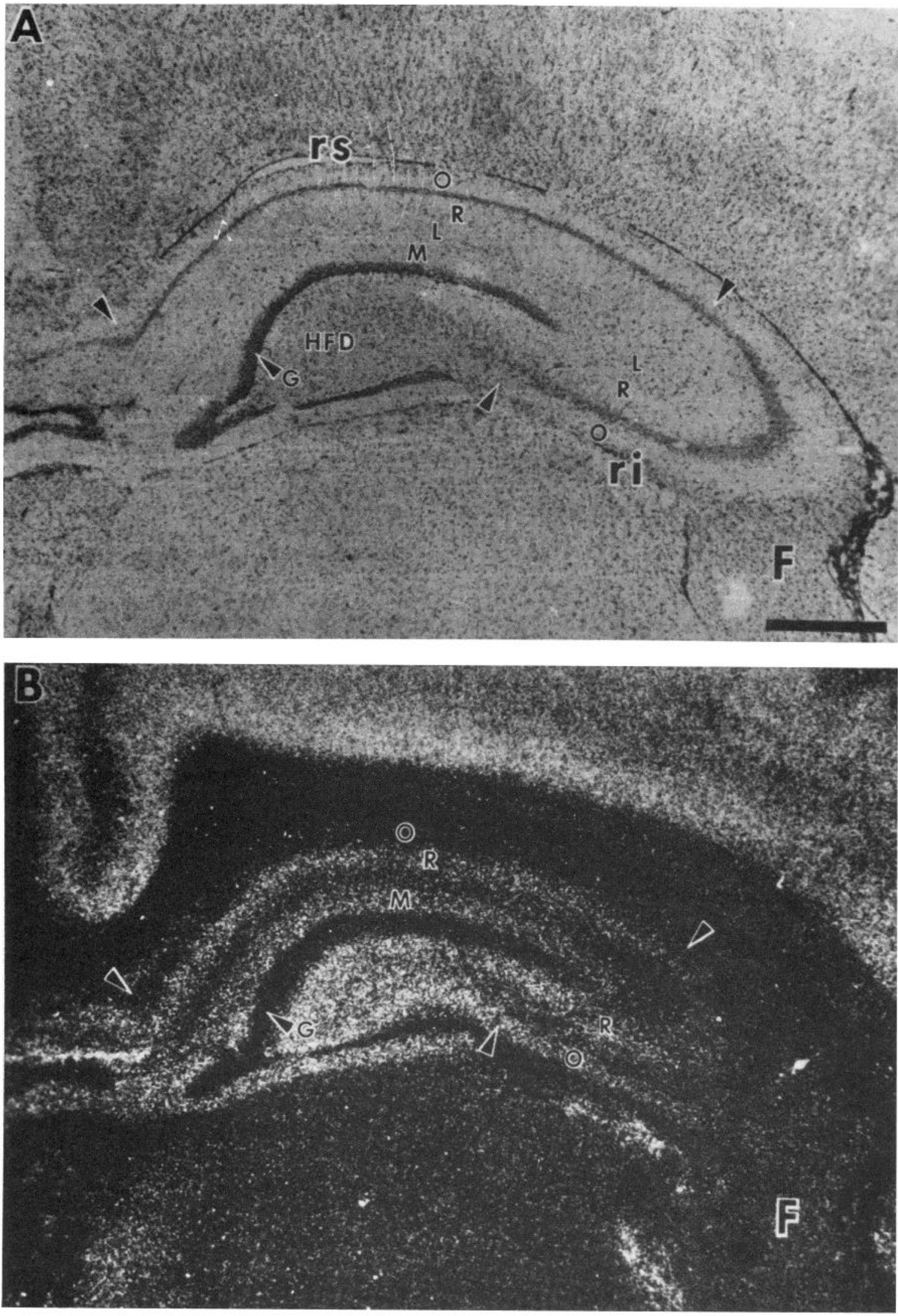

Figure 13. Distribution of CCK binding sites in the guinea pig hippocampus. $A$, Brightfield photomicrograph of the guinea pig hippocampal area (coronal plane). B, Darkfield photomicrograph of $A$. Unlabeled arrowheads mark the borders of regio superior ( $r s$ ) and regio inferior ( $r i)$. $F$, fimbria of the hippocampus; $G$, granule cell layer of the dentate gyrus; $H F D$, hilus fasciae dentatae; $L$, lamina lacunosum-moleculare; $M$, molecular layer of the dentate gyrus; $O$, stratum oriens; $R$, stratum radiatum. $B a r=769 \mu \mathrm{m}$. 

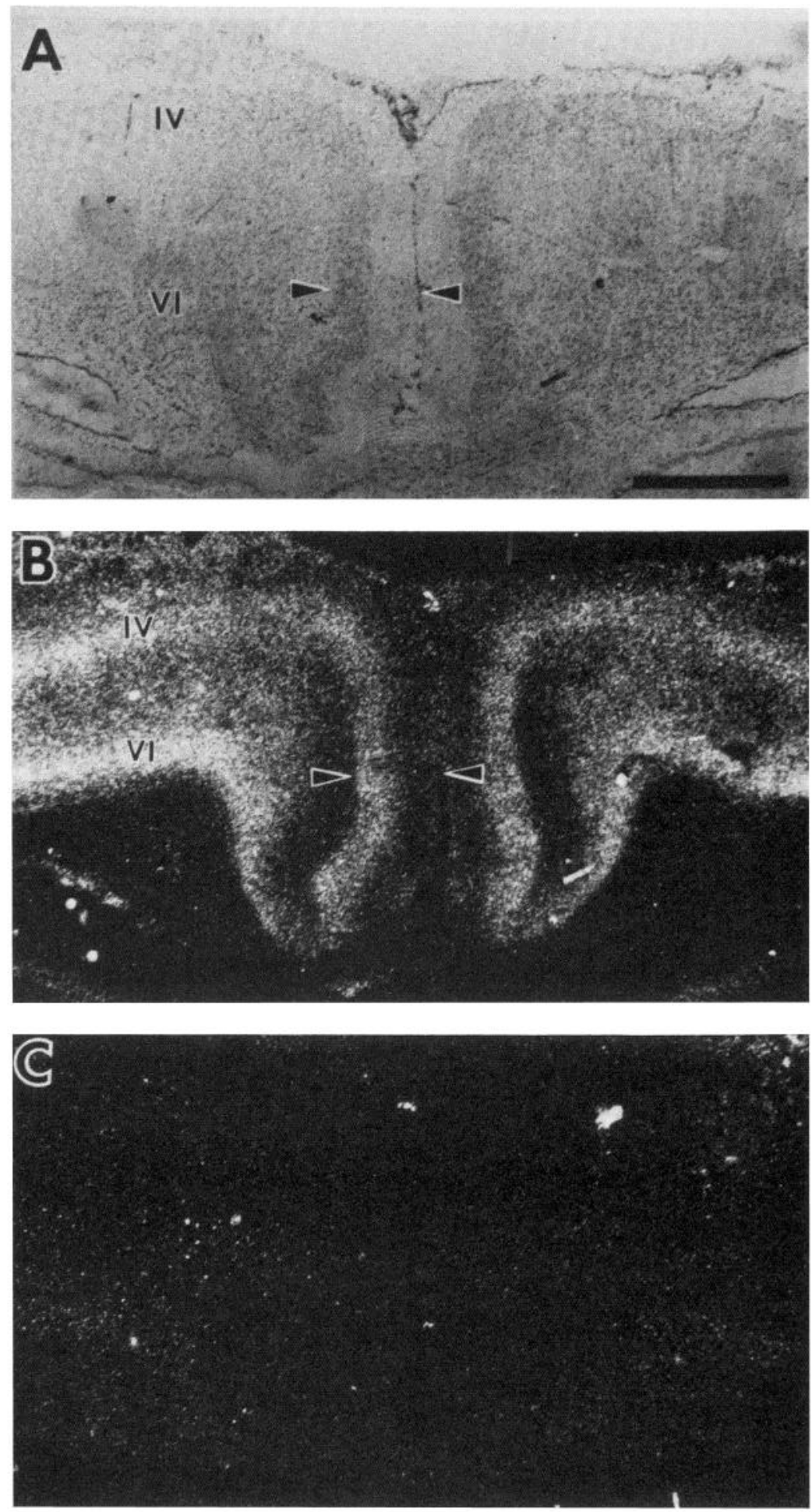

Figure 14. Distribution of CCK binding sites in the anterior cingulate cortex of the guinea pig. $A$, Brightfield photomicrograph of an autoradiogram of the guinea pig cerebral cortex (coronal plane). $B$, Darkfield photomicrograph of the autoradiogram shown in $A$. Opposing arrowheads mark the boundaries of lamina IV (left) and lamina I (right). Laminae $I V$ and $V I$ are indicated. $C$, Darkfield photomicrograph of an autoradiogram generated by incubating a tissue section consecutive to the one shown in $A$ in the presence of $50 \mathrm{pM}\left[{ }^{125} \mathrm{I}\right] \mathrm{CCK}-33$ and $10^{-7} \mathrm{M}$ CCK -8 . The diffusely distributed, low density of grains in $C$ represents nonspecific binding. See the text for discussion. Bar $=2667 \mu \mathrm{m}$.

in the white matter underlying the granular layer. Autoradiographic grains were around and over the somata of the Purkinje cells.

The area postrema contained the highest density of binding sites in the medulla pons (Fig. 22). White matter tracts, such as the spinal tract of the trigeminal nerve and the inferior cerebellar peduncle, contained only negligible grain densities. 

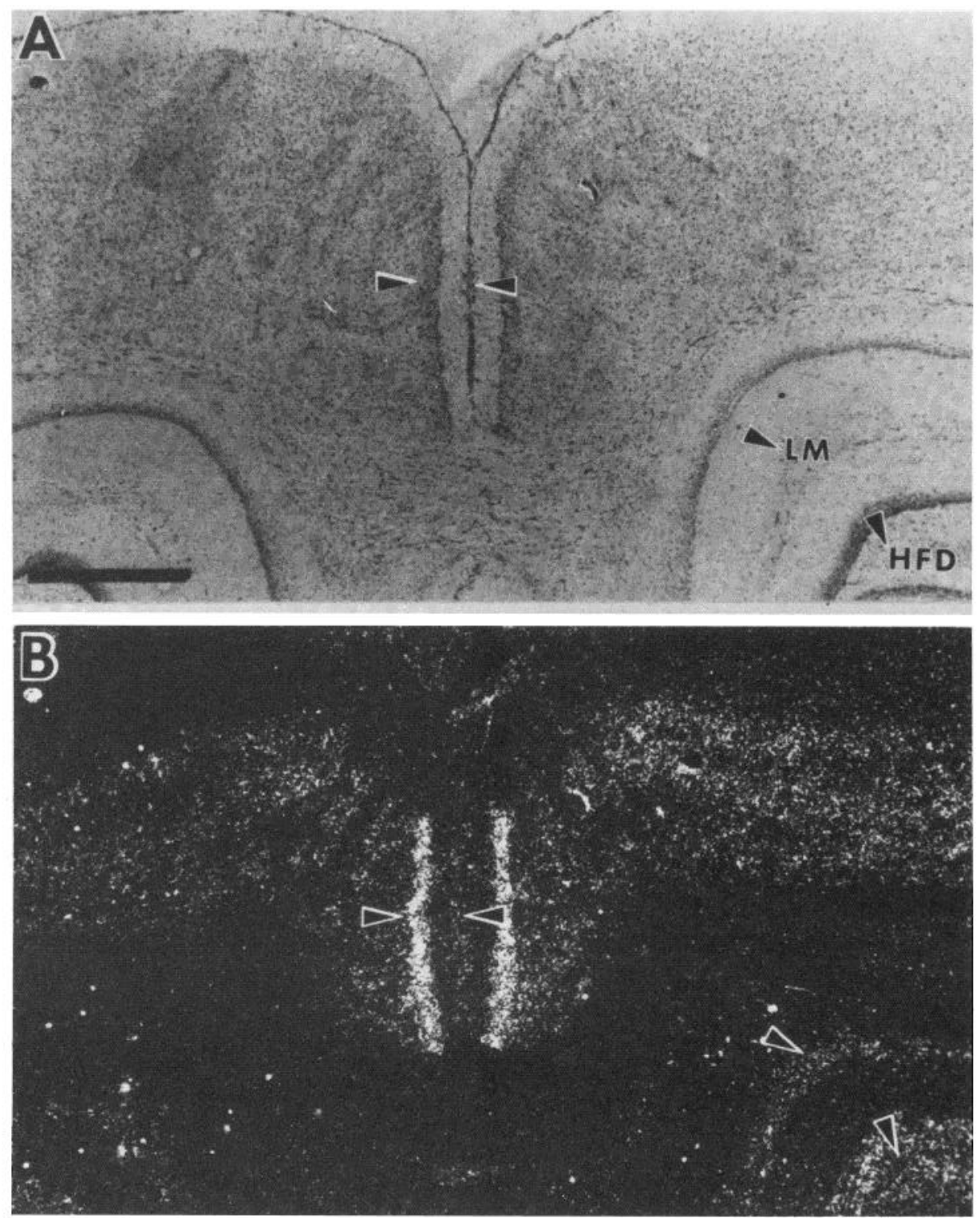

Figure 15. Distribution of CCK binding sites in the rat anterior cingulate cortex. A, Brightfield photomicrograph of an autoradiogram of the rat cerebral cortex (coronal plane). $B$, Darkfield photomicrograph of the autoradiogram shown in $A$. The opposing arrowheads mark the boundary of lamina IV (left) and lamina I (right) of the cingulate cortex. Parts of the septal (dorsal) hippocampal area can be seen in the lower right quandrant of $A$ and $B$. Abbreviations: $H F D$, hilus fasciae dentatae; $L M$, molecular layer of the hippocampus. See the text for discussion. Bar $=1667 \mu \mathrm{m}$.

Some areas of high grain density in the rat brainstem include the interpeduncular nucleus, the parabigeminal nucleus, and the caudal part of the nucleus linearis.

Spinal cord. The autoradiographic grains in the dorsal horn appeared to be concentrated in laminae I and II (not shown). A lower but significant grain density was present in the ventral horn.

\section{Discussion}

The kinetic characteristics and peptide specificity of $\left[{ }^{125} \mathrm{I}\right] \mathrm{CCK}-33$ binding to slide-mounted tissue sections are similar to those of $\left.{ }^{[25} \mathrm{I}\right] \mathrm{CCK}-33$ binding to membrane homogenate preparations. Thus, the CCK binding sites identified in this report correspond to those studied by other binding techniques and identify a physiologically relevant CCK receptor (Saito et al., 1980, 1981a; Innis and Snyder, 1980a, b; Hays et al., 1980).

Relationship between CCK nerve terminals and CCK binding site densities. Areas of apparent correspondence between the distribution of CCK immunoreactive (CCKIR) nerve terminals and the $\left[{ }^{125} \mathrm{I}\right] \mathrm{CCK}-33$ binding site include the spinal cord (e.g., dorsal horn), the brainstem (e.g., area postrema and possibly the dorsal tegmental nucleus), the neocortex (e.g., laminae II to IV of cingulate cortex), the basal ganglia (e.g., the caudate-putamen), and the pyriform cortex (including the prepyriform, periamygdaloid, and entorhinal cortices). If one also considers radioimmunoassay data (Larsson and Rehfeld, 1979), it seems that the high CCK binding site density in the olfactory lobe is matched by an equally high concentration of CCK immunoreactivity in that structure.

Some areas in which the distribution of CCK-IR nerves 

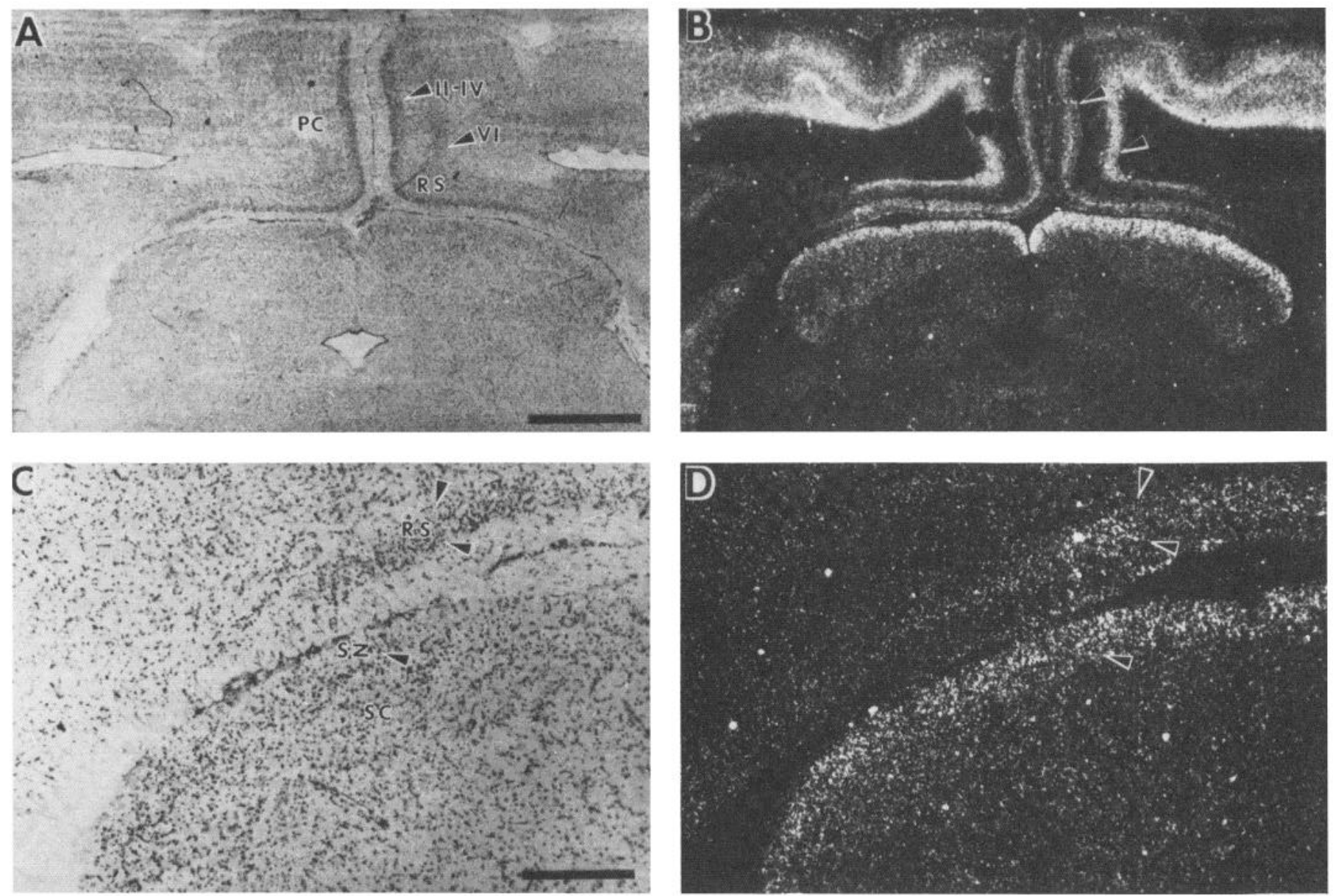

Figure 16. Distribution of CCK binding sites in the guinea pig midbrain. A, Brightfield photomicrograph of an autoradiogram of the guinea pig superior colliculus and cingulate cortex (coronal plane). Bar $=1736 \mu \mathrm{m} . B$, Darkfield photo of $A$. The arrowheads point to laminae $I I$ to $I V$ and lamina $V I$ of the posterior cingulate cortex $(P C)$. $C$, Higher magnification photo of the superficial lamina of the superior colliculus shown in $A$. Bar $=434 \mu \mathrm{m}$. D. Darkfield photo of $C$. The opposing arrowheads mark the borders of laminae II to III of the retrosplenial cortex $(R S)$. The single arrowhead indicates the stratum zonale of the superior colliculus $(S Z)$. SC, stratum cinereum of the superior colliculus. See the text for discussion.

and $\left[{ }^{125} \mathrm{I}\right] \mathrm{CCK}-33$ binding seem to be discordant are the amygdala, the hippocampus, and the cerebellum. For example, in the amygdala, two studies (Larsson and Rehfeld, 1979; Stengaard-Pedersen and Larsson, 1981), have indicated that the medial amygdaloid nucleus, an area of low $\left[{ }^{125} \mathrm{I}\right] \mathrm{CCK}-33$ binding site density, contains a high density of CCK-IR. However, some of the CCK immunoreactivity in the medial amygdala could be associated with fibers en passage (Stengaard-Pederson and Larsson, 1981) so that one would not anticipate associated receptors (see, for example, de Olmos and Ingram, 1972; de Olmos, 1972).

The guinea pig cerebellum provides the most striking example of a disparity between the anatomical distribution of CCK-IR nerves and $\left[{ }^{125} \mathrm{I}\right] \mathrm{CCK}-33$ binding sites. The density of CCK-IR nerves in the cerebellum is very low (Larsson and Rehfeld, 1979; Stengaard-Pedersen and Larsson, 1981). The density of cerebellar $\left[{ }^{125} \mathrm{I}\right] \mathrm{CCK}-33$ binding sites, on the other hand, is one of the highest in the central nervous system.

Similar discrepancies have been noted in studies of other neurotransmitter binding sites (Palacios and Kuhar, 1980; Palacios et al., 1980; Wamsley et al., 1982).
Several explanations for discordant transmitter and binding site distributions have been suggested. They are: that the transmitter is associated with fibers en passage, that the binding site is not confined to the subsynaptic area of the neural surface, and that the binding site may be associated with non-neural as well as neural elements. Some other conditions which could result in discrepant transmitter and binding site dispositions are as follows. The storage depot of a transmitter candidate need not be closely apposed to its binding site in order for the two elements to have a functional relationship. CCK may very well exert some effects through a hormone-like action in the brain (Innis et al., 1979; Larsson and Rehfeld, 1979; Loren et al., 1979; Beinfeld et al., 1980; Vanderhaeghen et al., 1980; Brar et al., 1981; Della-Fera and Baile, 1979; Della-Fera et al., 1981). Technical limitations may prevent the complete and appropriate identification of loci containing the neurotransmitter candidate and/or the putative binding site. For example, multiple forms of CCK have been identified. Receptors in areas devoid of immunoreactive CCK may be associated with nerve terminals containing a form of CCK not recognized by the antisera used for immunohistochemistry (compare, for 

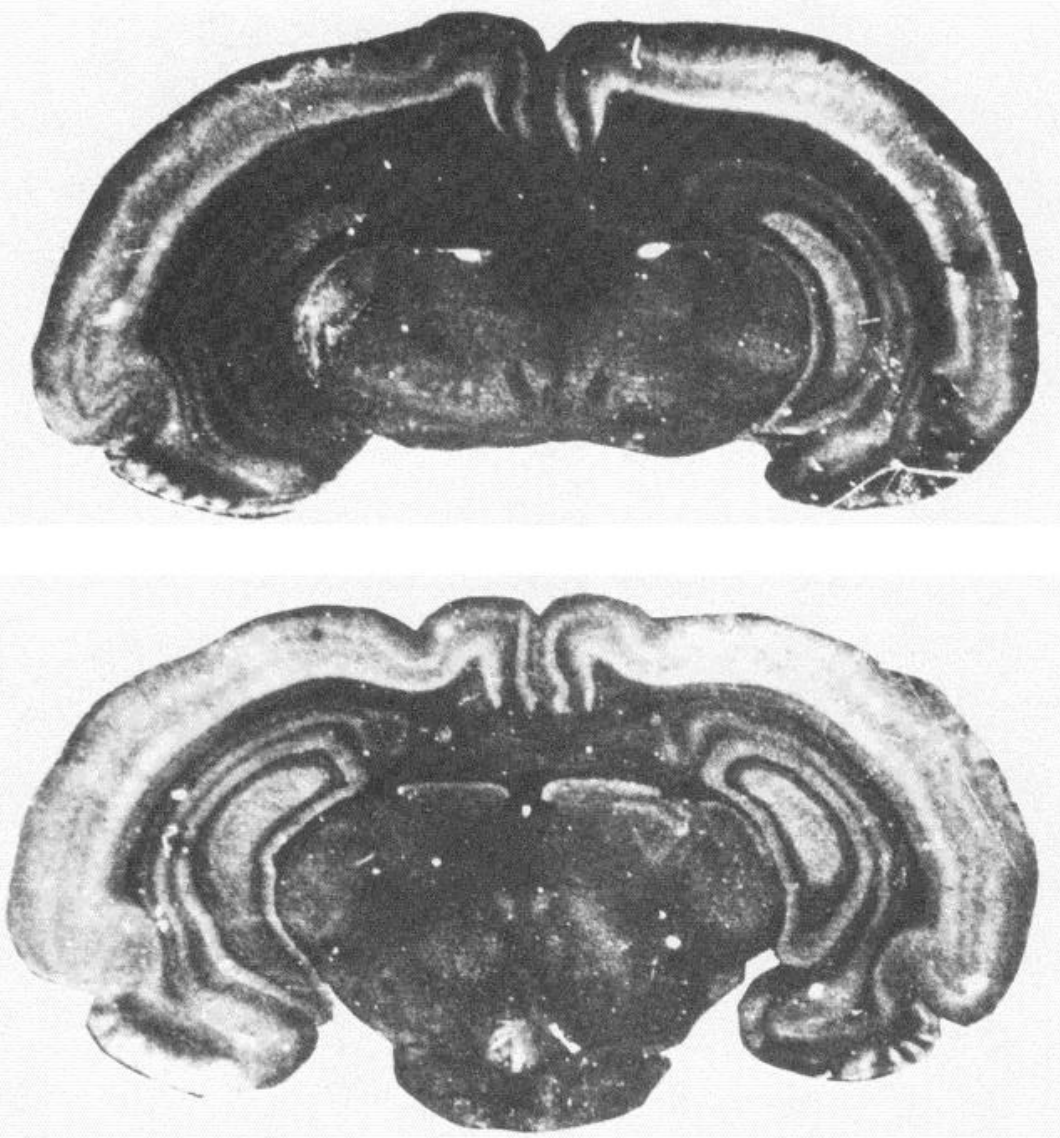

Figure 17. Distribution of CCK binding sites in the guinea pig brain. Two darkfield photomicrographs of autoradiograms at the level of the thalamus (top) and superior colliculus (bottom) are shown (coronal plane). The oval areas of very high grain density on either side of the midline in the top photo are the lateral parts of the nuclei of the optic tract. On the left-hand side of the top photo, an area of high density overlies the ventral lateral geniculate body which is situated ventrolateral to the nucleus of the optic tract. Note the high grain density over the interpeduncular nucleus in the bottom photograph. See the text for discussion. $B a r=4571 \mu \mathrm{m}$.

example, Innis et al., 1979 and Loren et al., 1979). Moreover, multiple forms of CCK binding sites exists (Innis and Snyder, 1980b). All relevant CCK binding sites may not have been labeled by $50 \mathrm{pm}\left[{ }^{125} \mathrm{I}\right] \mathrm{CCK}-33$. Due to technical limitations, the bulk of the CCK binding sites identified in this study are probably high affinity agonist binding sites. A better correlation between binding site and nerve terminal densities might be realized if low affinity CCK-33 binding sites were also visualized. Finally, because of spare or nonfunctional receptors, the quantitative relationship between the neurotransmitter and the binding site might not always be one to one.

Axonal localization of CCK binding sites. In the peripheral nervous system, CCK binding sites occur in the rat vagus nerve where they undergo transport (Zarbin et al., 1981a). CCK binding sites may also be found on some axons in the central nervous system, such as the guinea pig optic tract which has a high density of CCK receptors (Fig. 11). The high densities of binding sites in some of the areas of optic tract termination (e.g., in the pretectal area) are consistent with this possibility (Table III). In preliminary experiments, enucleation is followed by a drastic decrease in the density of binding sites in the pretectal area contralateral to the avulsed eyeball (R. B. Innis, M. A. Zarbin, S. H. Snyder, and M. J. Kuhar, manuscript in preparation).

The guinea pig and rat olfactory systems may provide another example of axonal CCK binding sites. Olfactory tract fibers ramify in discrete parts of the olfactory peduncle, pyriform cortex (e.g., laminae I and IA of the prepyriform cortex), and amygdala (e.g., the plexiform layer of the anterior cortical nucleus) (Lohman, 1963; White, 1965b; Scalia, 1966; Heimer, 1968; Lohman and Mentink, 1969; Price and Powell, 1971; Price, 1973). High densities of autoradiographic grains were found in each of these areas, suggesting that CCK binding sites are located on olfactory tract fibers. The distribution of autoradiographic grains within the guinea pig main and accessory olfactory bulbs and within the primary olfactory cortex (vide infra) suggests that either mitral cells, tufted cells (especially the internal tufted cell), or both cell types would be the source of these axonal binding sites and that these cells might possess CCK binding sites on their dendrites as well as on their axons (Cajal, 1911, 1955; Lohman, 1963; Lohman and Mentik, 1969; Haberly and Price, 1977). Of course, CCK binding sites 

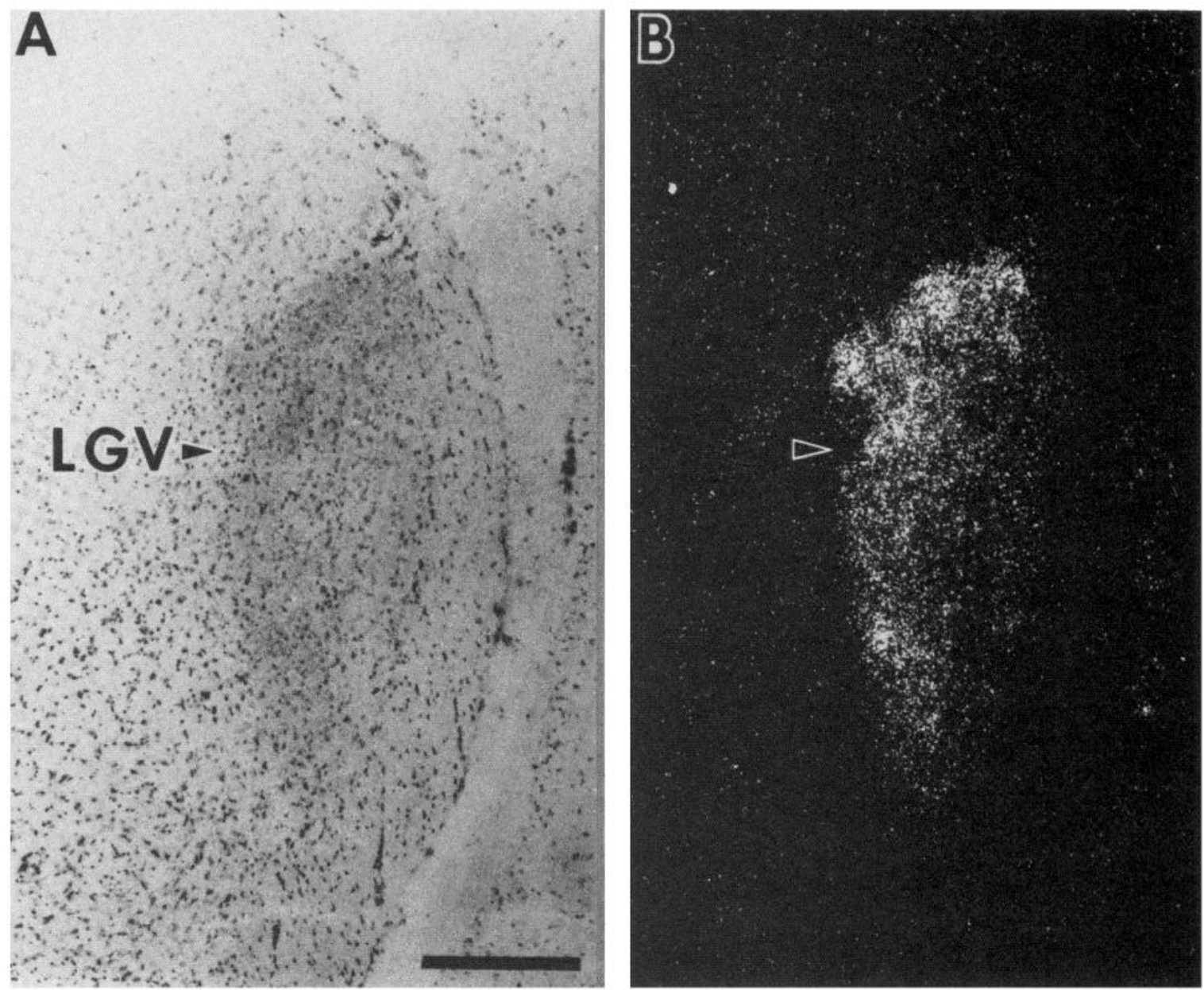

Figure 18. Distribution of CCK binding sites in the lateral geniculate body of the guinea pig. $A$, Brightfield photomicrograph of an autoradiogram of the ventral lateral geniculate body ( $L G V$; coronal plane). $B$, Darkfield photomicrograph of $A$. See the text for discussion. Bar $=400 \mu \mathrm{m}$.

in the primary olfactory cortex could also be associated with the apical dendrites of cells which received olfactory tract input and whose somata lie in deeper laminae.

Physiological systems associated with CCK binding sites. Although CCK binding sites are widely distributed in the central nervous system, some of the loci enriched in binding sites seem to be physiologically related either by receiving a common sensory input or by forming part of a more or less complete neuronal circuit.

Olfactory system. The distribution of CCK binding sites in the guinea pig paleopallium delineates the extent of the primary olfactory cortex as defined by O'Leary (1937), Pigache (1970), and others. As far as can be judged in the material examined, this generalization also seems to obtain in the rat. The high density of CCK binding sites in the olfactory bulb also attests to the association of CCK binding sites with the olfactory system. Regardless of whether the CCK binding sites are located on olfactory tract fibers or on the apical dendrites of pyramidal cells in the paleopallium (vide supra), the binding sites are situated in anatomical loci which would allow the modification of olfactory information at a very early point in its "entry" into CNS circuits. Inasmuch as CCK and its binding sites (including those in the olfac- tory bulb) seem to play a crucial role in the control of food intake (Antin et al., 1975; Smith and Gibbs, 1979; Stacher et al., 1979; Mueller and Hsiao, 1979; Ishibashi et al., 1979; Della-Fera and Baile, 1979; Schneider et al., 1979; Hays and Paul, 1981; Saito et al., 1981b), the anatomical distribution of CCK binding sites may suggest some of the loci which are involved in this effect. As the medial and lateral hypothalamic areas are known to be involved in the control of food intake (see Stevenson, 1969, Grossman, 1975, for references), olfactory impulses may ultimately affect feeding behavior by modulating hypothalamic function. Hypothalamic neural activity can be modulated by olfactory impulses relayed through a circuit involving the olfactory bulb, pyriform cortex and amygdala, and ventral subiculum (Lohman, 1963; Powell et al., 1965; Cain and Bindra, 1972; Dreifuss, 1972; Kretteck and Price, 1978a, b). CCK binding sites are present in moderate to high densities in various parts of the circuit. In the guinea pig, the density of binding sites in the hypothalamus appears to be low. Thus, if CCK regulates the feeding behavior of guinea pigs by acting at binding sites located in the CNS, it would seem to do so indirectly, via action in extrahypothalamic areas. Other olfactory-related behaviors, such as reproductive behav- 

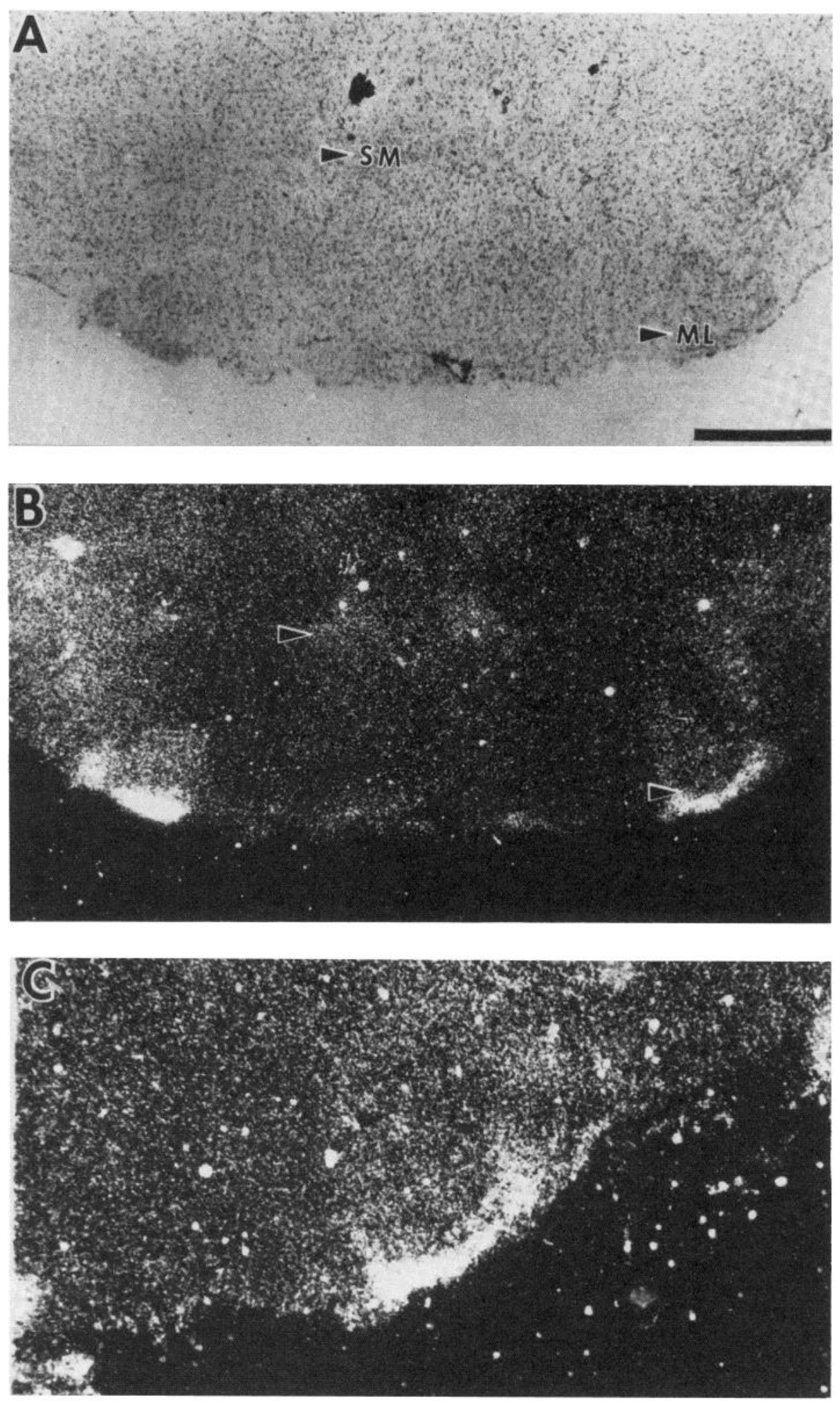

Figure 19. Distribution of CCK binding sites in the guinea pig mammillary nuclei. $A$, Brightfield photomicrograph of an autoradiogram of the guinea pig hypothalamus (coronal plane). Bar $=893 \mu \mathrm{m}$. B, Darkfield photo of $A$. The arrowheads indicate the location of the lateral mamillary body $(M L)$ and the superior mamillary nuclus $(S M)$. $C$, Higher magnification photo of $M L$ taken from $B$. Bar $=476 \mu \mathrm{m}$. See the text for discussion.

ior (Parker and Bruce, 1961; Heimer and Larsson, 1967; Powers and Winans, 1975), might also be modulated by CCK via parts of this circuit.

It has been suggested (Antin et al., 1975; Smith and
Gibbs, 1979) that CCK may act peripherally as well as centrally in the induction of satiety. Moreover, there is some evidence suggesting that CCK's principal site of action, with regard to feeding behavior, may be subject 

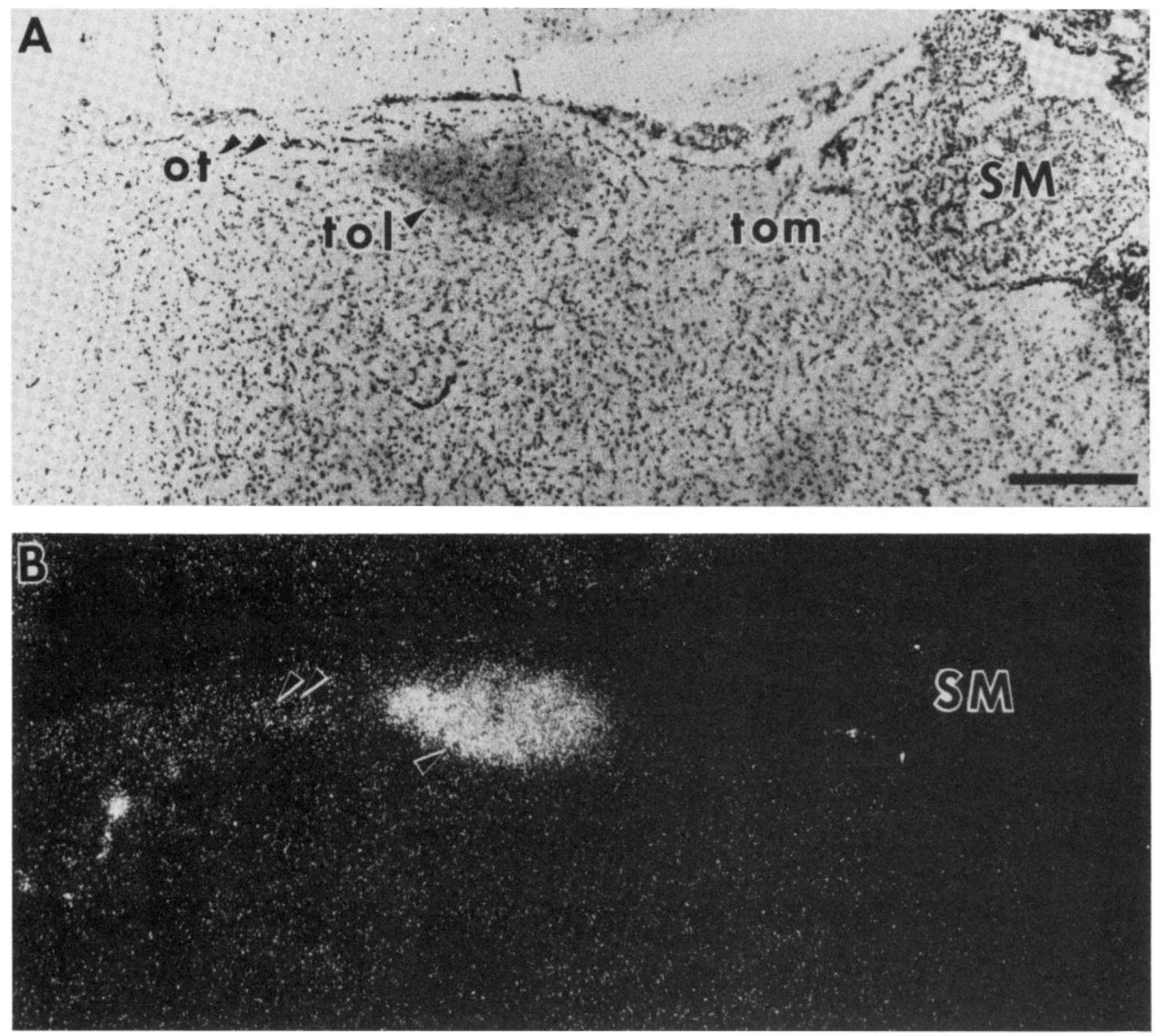

Figure 20. Distribution of CCK binding sites in the lateral part of the nucleus of the optic tract (tol) in the guinea pig. $A$, Brightfield photomicrograph of the nucleus of the optic tract (ot; coronal plane). $B$, Darkfield photomicrograph of $A$. Note the grains overlying the optic tract fibers (double arrowheads). SM, stria medullaris; tom, medial part of the nucleus of the optic tract. See the text for discussion. $B a r=385 \mu \mathrm{m}$.

to species variation (Della-Fera and Baile, 1979; DellaFera et al., 1981). The binding sites described in this study would correspond to the central locus of CCK action. In the rat, it seems that the vagus nerve is critically involved in peripherally administered CCK's ability to induce satiety (Lorenz and Goldman, 1978; Smith and Cushin, 1978; Smith et al., 1981). CCK binding sites have also been detected in the rat vagus nerve (Zarbin et al., 1981a). Part of the satiety effect induced by peripherally administered CCK could result from interaction with vagal CCK binding sites.

Other sensory systems. CCK binding sites were also localized to various parts of the guinea pig visual, auditory, and somatic sensory systems. The ability of CCK to cause sedation (Itoh and Katsuura, 1981; Zetler, 1981), ptosis (Zetler, 1980c), and analgesia (Zetler, 1980c; Jurna and Zetler, 1981; but compare Deschodt-Lanckman et al., 1981) may involve its action at binding sites associated with these systems and other areas (vide infra).

Limbic system. CCK binding sites are present in most of the structures which comprise the limbic lobe (White, 1965a). Various parts of the hippocampal formation are particularly enriched in CCK binding sites.

The finding that the ventral and dorsal subiculum differ with regard to their CCK binding site density may provide a biochemical demonstration that these two areas are functionally different, as was suggested by Swanson and Cowan (1977) on the basis of their anatomical data in the rat. The distribution of CCK binding sites in the entorhinal area and in the hippocampus and den- 

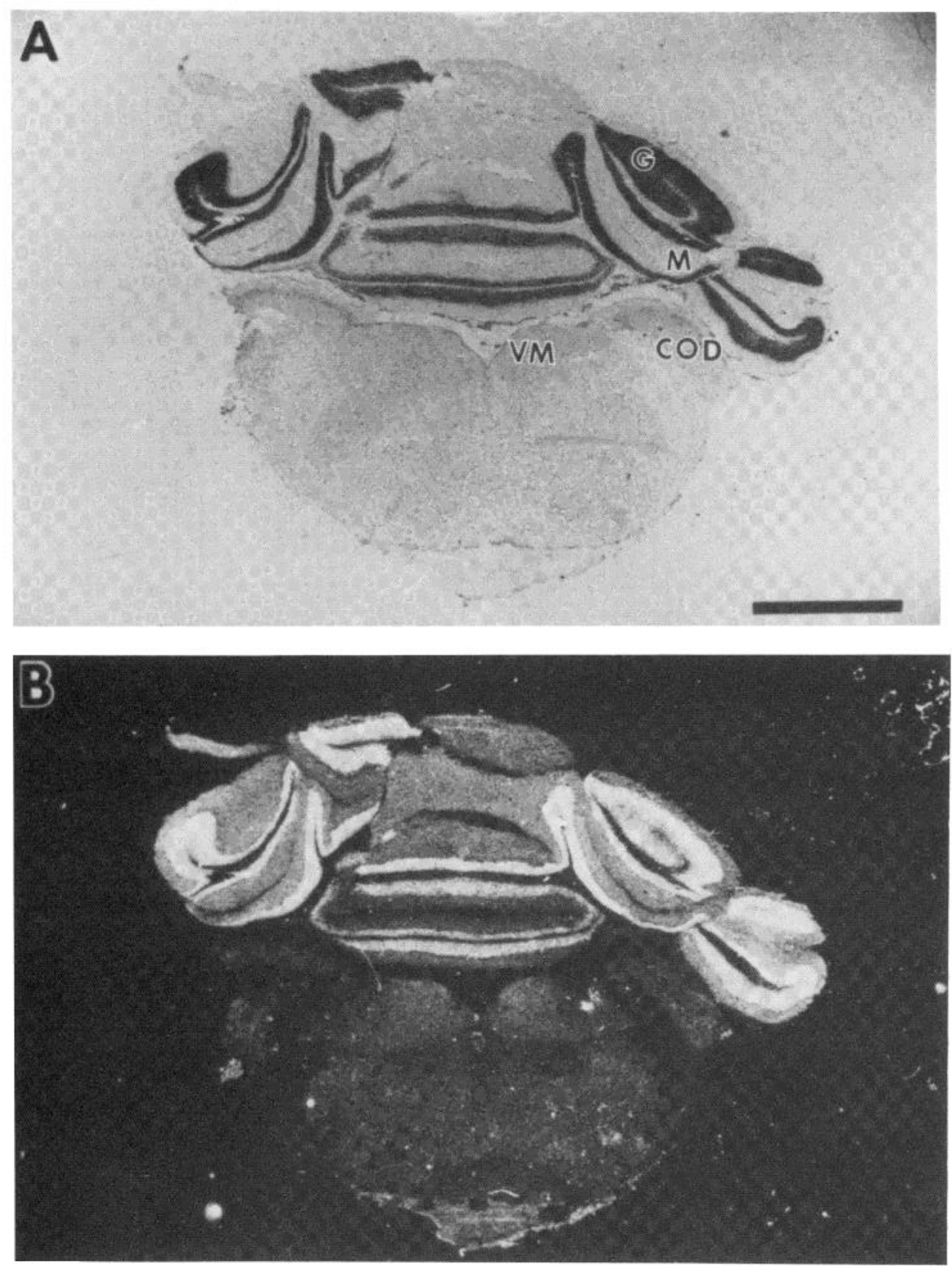

Figure 21. Distribution of CCK binding sites in the guinea pig cerebellum. A, Brightfield photomicrograph of an autoradiogram of the guinea pig cerebellum (horizontal plane). $B a r=2941 \mu \mathrm{m}$. $B$, Darkfield photo of $A$. $C O D$, dorsal cochlear nucleus; $G$, granule cell layer of the cerebellum; $M$, molecular layer of the cerebellum; $V M$, medial vestibular nucleus. See the text for discussion.

tate gyrus suggests that, within the hippocampal area, CCK binding sites may be located on axons as well as on dendrites (Shipley, 1975; Shipley and Sorensen, 1975; Cruce, 1975, 1977; Steward and Scoville, 1976; Fricke and Cowan, 1978; Kohler et al., 1978; Swanson et al., 1978). Finally, CCK may modulate certain activities such as feeding behavior (see above for references) and other behaviors (Zetler, 1980a, b, c, 1981; Itoh and Katsuura, 1981; Crawley et al., 1981a; but compare Crawley et al., 1981b), in part, by acting at these "limbic" CCK binding sites.

Co-localization of dopamine and CCK binding sites. The co-location of dopamine and CCK-containing nerves in many brain regions (compare, for example, Hokfelt et al., 1974; Lindvall et al., 1974; Berger et al., 1976; and
Larsson and Rehfeld, 1979; Innis et al., 1979; Loren et al., 1979; Vanderhaeghen et al., 1980; Williams et al., 1981) and the presence of CCK immunoreactivity in certain dopamine-containing neurons (Hokfelt et al., 1980b) has led to the suggestion (Hokfelt et al., 1980a) that CCK may modulate some aspects of dopaminergic neurotransmission. Electrophysiological data support this notion (Skirboll et al., 1981).

Binding sites for CCK and dopamine (Klemm et al., 1979; Murrin and Kuhar, 1979; Palacios et al., 1981), are co-localized in a number of brain areas, particularly in the limbic system. For example, CCK and dopamine binding sites occur in the interpeduncular nucleus, in the lateral mamillary nuclei, in the olfactory tubercle, and in the nucleus accumbens, as well as in other areas such as 

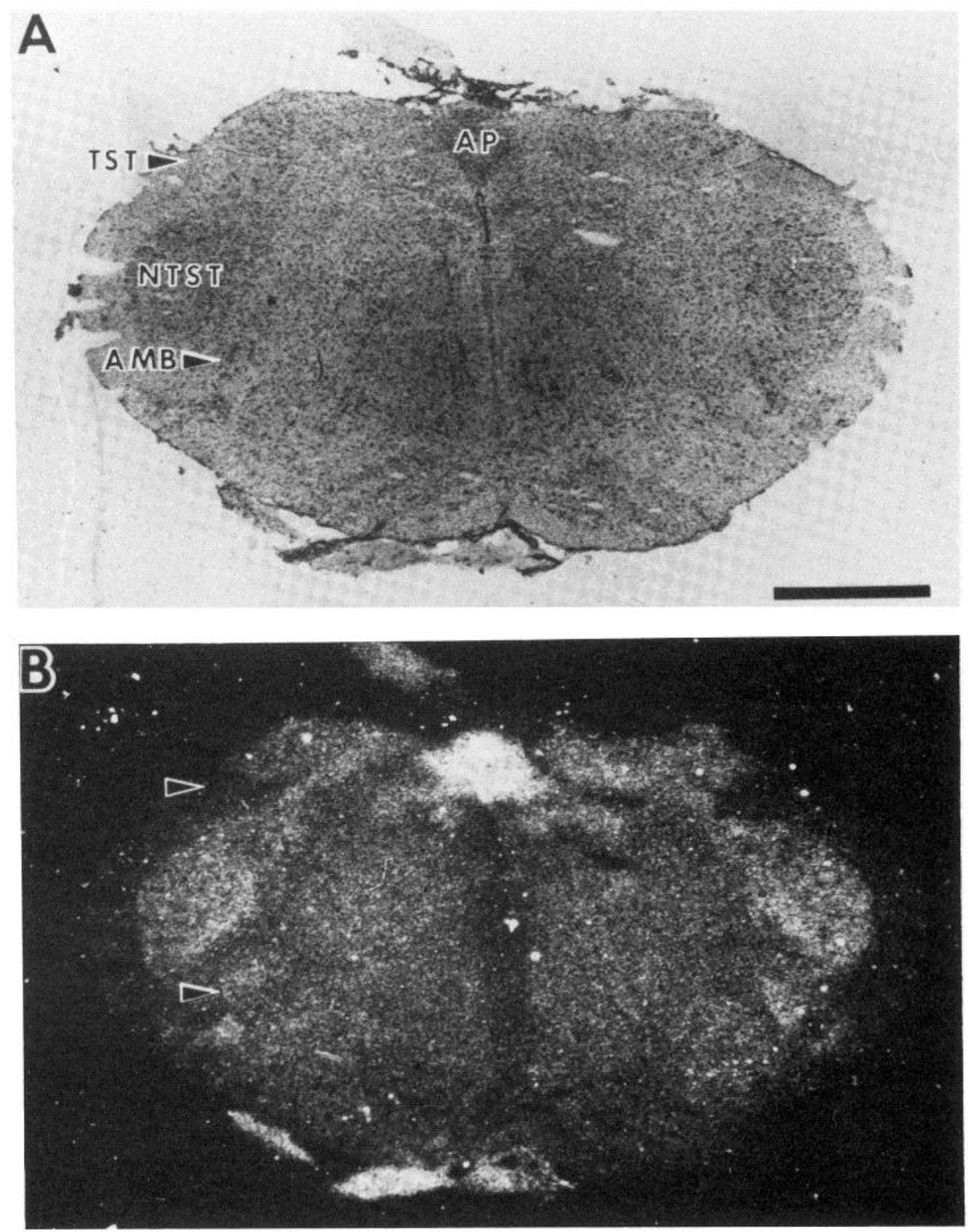

Figure 22. Distribution of CCK binding sites in the guinea pig medulla. A, Brightfield photomicrograph of an autoradiogram of the guinea pig medulla (horizontal plane). $B$, Darkfield photomicrograph of $A$. The arrowheads indicate the location of the spinal tract of the trigeminal nerve (TST; upper) and the nucleus ambiguus (AMB; lower). AP, area postrema; NTST, nucleus of the spinal tract of the trigeminal nerve. See the text for discussion. Bar $=1481 \mu \mathrm{m}$.

the substantia nigra, the caudate-putamen, and the lateral part of the nucleus of the optic tract. There are several areas, however, in which the distributions of CCK and dopamine binding sites seem to be discordant (the external plexiform layer of the olfactory bulb, parts of the hippocampus, the central amygdaloid nucleus, the arcuate nucleus of the hypothalamus, and other areas). The co-distribution of binding sites may be part of the neuronal mechanism involved in the CCK-dopamine interaction.

Preliminary reports of these findings have been presented elsewhere (Innis et al., 1981; Zarbin et al., 1981b).

\section{References}

Antin, J., J. Gibbs, J. Holt, R. C. Young, and G. P. Smith (1975) Cholecystokinin elicits the complete behavioral sequence of satiety in rats. J. Comp. Physiol. Psychol. 89: 784-790.

Beinfeld, M. C., D. K. Meyer, and M. J. Brownstein (1980) Cholecystokinin octapeptide in the rat hypothalamo-neurohypophysial system. Nature 288: 376-378.

Beinfeld, M. C., D. K. Meyer, R. L. Eskay, R. T. Jensen, and M. J. Brownstein (1981) The distribution of cholecystokinin immunoreactivity in the central nervous system of the rat as determined by radioimmunoassay. Brain Res. 212: 51-57.

Berger, B., A. M. Thierry, J. P. Tassin, and M. A. Moyne (1976) Dopaminergic innervation of the rat prefrontal cortex: A fluorescence histochemical study. Brain Res. 186: 133-145.

Blackstad, T. W. (1956) Commissural connections of the hippocampal region in the rat, with special reference to their mode of termination. J. Comp. Neurol. 105: 417-537.

Brar, A., G. J. Dockray, R. C. Dow, and G. Fink (1981) Cholecystokinin in rat hypophysial portal vessel blood. Neurosci. Lett. Suppl. (Abstr.) 7: S322.

Cain, D. P., and D. Bindra (1972) Responses of amygdala single 
units to odors in the rat. Exp. Neurol. 35: 98-110.

Crawley, J. N., S. E. Hays, T. L. O'Donohue, S. M. Paul, and F. K. Goodwin (1981a) Neuropeptide modulation of social and exploratory behaviors in laboratory rodents. Peptides 2 (Suppl. 1): 123.

Crawley, J. N., S. E. Hays, and S. M. Paul (1981b) Vagotomy abolishes the inhibitory effects of cholecystokinin on rat exploratory behaviors. Eur. J. Pharmacol. 73: 379-380.

Cruce, J. A. F. (1975) An autoradiographic study of the projections of the mammillothalamic tract in the rat. Brain Res. 85: 211-219.

Cruce, J. A. F. (1977) An autoradiographic study of the descending connections of the mammilary nuclei of the rat. J. Comp. Neurol. 176: 631-644.

Della-Fera, M. A., and C. A. Baile (1979) Cholecystokinin octapeptide: Continuous picomole injections into the cerebral ventricles of sheep suppress feeding. Science 206: 471-473.

Della-Fera, M. A., C. A. Baile, B. S. Schneider, and J. A. Grinker (1981) Cholecystokinin antibody injected in cerebral ventricles stimulates feeding in sheep. Science 212: 687-689.

de Olmos, J. S. (1972) The amygdaloid projection field in the rat as studied with the cupric silver method. In The Neurobiology of the Amygdala, B. E. Eleftheriou, ed., pp. 145-204, Plenum Press, New York.

de Olmos, J. S., and W. R. Ingram (1972) The projection field of the stria terminalis in the rat brain. An experimental study. J. Comp. Neurol. 146: 303-334.

Deschodt-Lankman, M., N. D. Bui, and J. Christophe (1981) Cholecystokinin octa and tetrapeptide degradation by synaptic membranes. Evidence for competition with enkephalin. for common degradation pathways. Neurosci. Lett. Suppl. (Abstr) 7: S321.

Dockray, G. J. (1976) Immunochemical evidence of cholecystokinin-like peptides in brain. Nature 264: 568-570.

Dreifuss, J. J. (1972) Effects of electrical stimulation of the amygdaloid complex on the ventromedial hypothalamus. In The Neurobiology of the Amygdala, B. E. Eleftheriou, ed., pp. 295-317, Plenum Press, New York.

Flores, A. (1911) Die Myeloarchitektonik und die Myelogenic des Cortex Cerebri beim Igel (Erinaceus europaeus). J. Psychol. Neurol. 17: 215-247.

Fricke, R., and W. M. Cowan (1978) An autoradiographic study of the commissural and ipsilateral hippocampo-dentate projections in the adult rat. J. Comp. Neurol. 181: 253-270.

Geneser-Jensen, F. A., and T. W. Blackstad (1971) Distribution of acetylcholinesterase in the hippocampal region of the guinea pig. I. Entorhinal area, parasubiculum and presubiculum. Z. Zellforsch. 114: 460-481.

Grossman, S. P. (1975) Role of the hypothalamus in the regulation of food and water inlake. Psychol. Rev. 82: 200-224.

Haberly, L. B., and J. L. Price (1977) The axonal projection patterns of the mitral and tufted cells of the olfactory bulb in the rat. Brain Res. 129: 152-157.

Hall, E., and F. A. Geneser-Jensen (1971) Distribution of acetylcholinesterase and monoamine oxidase in the amygdala of the guinea pig. Z. Zellforsch. 120: 204-221.

Harper, A. A., and H. S. Raper (1943) Pancreozymin; a stimulant of the secretion of pancreatic enzymes in extracts of the small intestine. J. Physiol (Lond.) 102: 115-125.

Hays, S. E., and S. M. Paul (1981) Cholecystokinin receptors are increased in cerebral cortex of genetically obese rodents. Eur. J. Pharmacol. 70: 591-592.

Hays, S. E., M. C. Beinfeld, R. T. Jensen, F. K. Goodwin, and S. M. Paul (1980) Demonstration of a putative receptor site for cholecystokinin in rat brain. Neuropeptides 1: 53-62.

Heimer, L. (1968) Synaptic distribution of centripetal and centrifugal nerve fibers in the olfactory system of the rat. An experimental anatomical study. J. Anat. 103: 413-432.
Heimer, L., and K. Larsson (1967) Mating behavior of male rats after olfactory bulb lesions. Physiol. Behav. 2: 207-209.

Herrick, C. J. (1924) The nucleus olfactorius anterior of the opposum. J. Comp. Neurol. 17: 317-359.

Hokfelt, T., A. Ljungdahl, K. Fuxe, and O. Johansson (1974) Dopamine nerve terminal in rat limbic cortex: Aspects of the dopamine hypothesis of schizophrenia. Science 184: 177-179.

Hokfelt, T., O. Johansson, A. Ljungdahl, J. M. Lundberg, and M. Schultzberg (1980a) Peptidergic neurons. Nature 284: 515-521.

Hokfelt, T., J. F. Rehfeld, L. Skirboll, B. Ivemark, M. Goldstein, and K. Markey (1980b) Evidence for coexistence of dopamine and CCK in mesolimbic neurons. Nature 285: 476-478.

Innis, R. B., and S. H. Snyder (1980a) Cholecystokinin receptor binding in brain and pancrease: Regulation by acyclic and cyclic guanine nucleotides. Eur. J. Pharmacol. 65: 123-124.

Innis, R. B., and S. H. Snyder (1980b) Distinct cholecystokinin receptors in brain and pancreas. Proc. Natl. Acad. Sci. U. S. A. 77: 6917-6921.

Innis, R. B., F. M. Correa, G. R. Uhl, B. Schneider, and S. H. Snyder (1979) Cholecystokinin octopeptide-like immunoreactivity: Histochemical localization in rat brain. Proc. Natl. Acad. Sci. U. S. A. 76: 521-525.

Innis, R. B., M. A. Zarbin, J. K. Wamsley, S. H. Snyder, and M. J. Kuhar (1981) Autoradiographic localization of cholecystokinin receptors in guinea pig brain. Soc. Neurosci. Abstr. 7 : 430 .

Ishibashi, S., Y. Oomura, T. Okajima, and S. Shibata (1979) Cholecystokinin, motilin and secretin effects on the central nervous system. Physiol. Behav. 23: 401-403.

Itoh, S., and G. Katsuura (1981) Sedative action of intracerebroventricularly administered cholecystokinin in the rat. Neurosci. Lett. Suppl. (Abstr.) 7: S323.

Ivy, A. C., and E. Oldberg (1928) Hormone mechanism for gallbladder contraction and evacuation. Am. J. Physiol. 86: 599-613.

Johnson, T. N. (1959) Studies of the brain of the guinea pig. II. The olfactory tracts and fornix. J. Comp. Neurol. 112: 121140 .

Jurna, I., and G. Zetler (1981) Antinociceptive effect of centrally administered caerulein and cholecystokinin octapeptide. Eur. J. Pharmacol. 73: 323-331.

Klemm, N., L. C. Murrin, and M. J. Kuhar (1979) Neuroleptic and dopamine receptors: Autoradiographic localization of ${ }^{3} \mathrm{H}$ spiperone in rat brain. Brain Res. 169: 1-9.

Kohler, C., M. T. Shipley, B. Srebro, and W. Harkmark (1978) Some retrohippocampal afferents to the entorhinal cortex. Cells of origin as studied by the HRP method in the rat and mouse. Neurosci. Lett. 10: 115-120.

Kretteck, J. E., and J. L. Price (1977) Projections from the amygdaloid complex and adjacent olfactory structures to the entorhinal cortex and to the subiculum in the rat and cat. J. Comp. Neurol. 172: 723-752.

Kretteck, J. E., and J. L. Price (1978a) A description of the amygdaloid complex in the rat and cat with observations on intra-amygdaloid axonal projections. J. Comp. Neurol. 178. $255-280$.

Kretteck, J. E., and J. L. Price (1978b) Amygdaloid projection to subcortical structures within the basal forebrain and brainstem in the rat and cat. J. Comp. Neurol. 178: 225-254.

Krieg, W. S. (1946a) Connections of the cerebral cortex. I. The albino rat A. Topography of the cortical areas. J. Comp. Neurol. 84: 221-275.

Krieg, S. W. (1946b) Connections of the cerebral cortex. I. The albino rat B. Structure of the cortical areas. J. Comp. Neurol. 84: $277-323$

Larsson, L. -I., and J. F. Rehfeld (1979) Localization and molecular heterogeneity of cholecystokinin in the central and 
peripheral nervous system. Brain Res. 165: 201-218.

Leonard, C. M., and J. W. Scott (1971) Origin and distribution of the amygdalofugal pathways in the rat: An experimental neuroanatomical study. J. Comp. Neurol. 141: 313-330.

Lindvall, O., A. Bjorklund, R. Y. Moore, and V. Stenevi (1974) Mesencephalic dopamine neurons projecting to the neocortex. Brain Res. 81: 325-337.

Lohman, A. H. M. (1963) The anterior olfactory lobe of the guinea pig. A descriptive and experimental anatomical study. Acta. Anat. (Basel) 53 (Suppl. 49): 1-109.

Lohman, A. H. M., and G. M. Mentink (1969) The lateral olfactory tract, the anterior commissure and the cells of the olfactory bulb. Brain Res. 12: 396-413.

Loren, I., J. Alumets, R. Hakanson, and F. Sundler (1979) Distribution of gastrin and CCK-like peptides in rat brain. Histochemistry 59: 249-257.

Lorente de No, K. (1934) Studies on the structure of the cerebral cortex. II. Continuation of the study of the ammonic system. J. Psychol. Neurol. 46: 113-177.

Lorenz, D. N., and S. A. Goldman (1978) Dependence of the cholecystokinin satiety effect on vagal denervation. Soc. Neurosci. Abstr. 4: 178.

Mueller, K., and S. Hsiao (1979) Consistency of cholecystokinin satiety effect across deprivation levels and motivational states. Physiol. Behav. 22: 804-815.

Murrin, L. C., and M. J. Kuhar (1979) Dopamine receptors in the rat frontal cortex: An autoradiographic study. Brain Res. 177: 279-285

Mutt, V., and J. E. Jorpes (1966) Structure of porcine cholecystokinin-pancreaozymin. I. Cleavage with thrombin and with trypsin. Eur. J. Biochem. 6: 156-162.

O'Leary, J. L. (1937) Structure of the primary olfactory cortex of the mouse. J. Comp. Neurol. 67: 1-31.

Palacios, J. M., and M. J. Kuhar (1980) Beta-adrenergic receptor localization by light microscopic autoradiography. Science 208: 1378-1380.

Palacios, J. M., W. S. Young, III, and M. J. Kuhar (1980) Autoradiographic localization of gamma-aminobutyric acid (GABA) receptors in the rat cerebellum. Proc. Natl. Acad. Sci. U. S. A. 77: 670-674.

Palacios, J. M., D. L. Niehoff, and M. J. Kuhar (1981) ${ }^{3} \mathrm{H}$ Spiperone binding sites in brain: Autoradiographic localization of multiple receptors. Brain Res. 213: 277-289.

Parker, A. S., and H. M. Bruce (1961) Olfactory stimuli in mammalian reproduction. Science 134: 1049-1054.

Pigache, R. M. (1970) The anatomy of "paleocortex." A critical review. Ergeb. Anat. Entwickl. Gesch. 43: 1-62.

Powell, T. P. S., W. M. Cowan, and G. R. Raisman (1965) The central olfactory connections. J. Anat. 99: 791-813.

Powers, J. B., and S. S. Winans (1975) Vomeronasal organ: Critical role in mediating sexual behavior of the male hamster. Science 187: 961-963.

Price, J. L. (1973) An autoradiographic study of complimentary laminar patterns of termination of afferent fibers to the olfactory cortex. J. Comp. Neurol. 150: 87-108.

Price, J. L., and T. P. S. Powell (1971) Certain observations on the olfactory pathway. J. Anat. 110: 105-126.

Romon y Cajal, S. (1911) Histologie du Systeme Nerveux de L'Homme et des Vertebres, Maloine, Paris.

Romon y Cajal, S. (1955) Studies on the Cerebral Cortex, Limbic Structures, Lloyd-Duke, Ltd., London.

Rehfeld, J. F. (1977) Gastrine and cholecystokinin in brain and gut. Acta Pharmacol. Toxicol. 24: 44.

Rehfeld, J. F. (1980) Cholecystokinin. Clin. Gastroenterol. 9: 593-607.

Rose, J. E., and C. N. Woolsey (1948) Structure and relations of limbic cortex and anterior thalamic nuclei in rabbit and cat. J. Comp. Neurol. 89: 229-347.
Rose, M. (1912) Histologische Lokalisation der Grosshirnrinde bei Kleinen Saugetieren (Rodentia, Insectivora, Chiroptera). J. Psychol. Neurol. 19: 391-479.

Rose, M. (1927) Gyrus Limbicus anterior und Regio retrosplenialis (cortex holoprotoptychos guinguestratificatus) Vergleichende Architektonik beir Tier und Mensch. J. Psychol. Neurol. 35: 66-111.

Saito, A., H. Sankaran, I. D. Goldfine, and J. A. Williams (1980) Cholecystokinin receptors in the brain: Characterization and distribution. Science 208: 1155-1156.

Saito, A., I. D. Goldfine, and J. A. Williams (1981a) Characterization of receptors for cholecystokinin and related peptides in mouse cerebral cortex. J. Neurochem. 37: 483-490.

Saito, A., J. A. Williams, and I. D. Goldfine (1981b) Alterations in brain cholecystokinin receptors after fasting. Nature 289: $599-600$.

Sankaran, H., I. D. Goldfine, C. W. Deveney, K. -Y. Wang, and J. A. Williams (1980) Binding of cholecystokinin to high affinity receptors on isolated rat pancreatic acini. J. Biol. Chem. 255: 1849-1853.

Scalia, F. (1966) Some olfactory pathways in the rabbit brain. J. Comp. Neurol. 126: 285-310.

Schneider, B. S., J. W. Monahan, and J. Hirsch (1979) Brain cholecystokinin and nutritional status in rats and mice. J. Clin. Invest. 64: 1348-1356.

Shipley, M. T. (1975) The topographical and laminar organization of the presubiculum's projection to the ipsi- and contralateral entorhinal cortex in the guinea pig. J. Comp. Neurol. 160: 127-146.

Shipley, M. T., and K. E. Sorensen (1975) On the laminar organization of the anterior thalamus projections to the presubiculum in the guinea pig. Brain Res. 86: 473-477.

Skirboll, L., A. A. Grace, D. W. Hommer, J. Rehfeld, M. Goldstein, T. Hokfelt, and B. S. Bunney (1981) Peptide monoamine coexistence: Studies of the actions of cholecystokinin-like peptide on the electrical activity of midbrain dopamine neurons. Neuroscience 6: 2111-2124.

Smith, G. P., and B. J. Cushin (1978) Cholecystokinin acts at a vagally innervated abdominal site to elicit satiety. Soc. Neurosci. Abstr. 4: 180.

Smith, G. P., and J. Gibbs (1979) Postprandial satiety. Prog. Psychobiol. Physiol. Psychol. 8: 180-242.

Smith, G. P., C. Jerome, B. J. Cushin, R. Eterno, and K. J. Simansky (1981) Abdominal vagotomy blocks the satiety effect of cholecystokinin in the rat. Science 213: 1036-1037.

Stacher, G., H. Bauer, and H. Steinringer (1979) Cholecystokinin decreases appetite and activation evoked by stimuli arising from the preparation of a meal in man. Physiol. Behav. 23: $325-331$.

Stengaard-Pedersen, K., and L. -I. Larsson (1981) Localization and opiate receptor binding of enkephalin, CCK, and ACTH/ beta-endorphin in the rat central nervous system. Peptides 2: 3-19.

Stevenson, J. A. F. (1969) Neural control of food and water intake. In The Hypothalamus, W. Haymaker, E. Anderson, and W. J. H. Nauta, eds., pp. 524-621, Charles C Thomas, Springfield, IL.

Steward, O., and S. A. Scoville (1976) Cells of origin of entorhinal cortical afferents to the hippocampus and fascia dentata of the rat. J. Comp. Neurol. 169: 347-370.

Strauss, E., and R. S. Yalow (1978) Species specificity of cholecystokinin in gut and brain of several mammalian species. Proc. Natl. Acad. Sci. U. S. A. 75: 486-489.

Swanson, L. W., and W. M. Cowan (1977) An autoradiographic study of the organization of the efferent connections of the hippocampal formatrion in the rat. J. Comp. Neurol. 172: 4984.

Swanson, L. W., J. M. Wyss, and W. M. Cowan (1978) An 
autoradiographic study of the organization of intrahippocampal association pathways in the rat. J. Comp. Neurol. 181: 681-716.

Unnerstall, J. R., M. J. Kuhar, D. L. Niehoff, and J. M. Palacios (1981) Benzodiazepine receptors are coupled to a subpopulation of GABA receptors: Evidence from a quantitative autoradiographic study. J. Pharmacol. Exp. Ther. 218: 797804.

Vanderhaeghen, I. .J., F. Totstra, .J. De Mey, and C. Gilles (1980) Immunohistochemical localization of cholecystokinin and gastrin-like peptides in the brain and hypophysis of the rat. Proc. Natl. Acad. Sci. U. S. A. 77: 1190-1194.

Vaz Ferreira, A. (1951) The cortical areas of the albino rat studied by silver impregnation. J. Comp. Neurol. 95: 177-243.

Wamsley, J. K., M. A. Zarbin, W. S. Young, III, and M. J. Kuhar (1982) Distribution of opiate receptors in the monkey brain: An autoradiographic study. Neuroscience 7: 595-613.

White, L. E., Jr. (1965a) A morphological concept of the limbic lobe. Int. Rev. Neurobiol. 8: 1-34.

White, L. E., Jr. (1965b) Olfactory bulb projections of the rat. Anat. Rec. 152: 465-480.

Williams, R. G., R. J. Gayton, W. -Y. Zhu, and G. J. Dockray (1981) Changes in brain cholecystokinin octapeptide follow- ing lesions of the medial forebrain bundle. Brain Res. 213: $227-230$

Young, W. S., III, and M. J. Kuhar (1979) A new method for receptor autoradiography: ${ }^{3} \mathrm{H}$-Opioid receptors in rat brain. Brain Res. 179: 255-270.

Zarbin, M. A., J. K. Wamsley, R. B. Innis, and M. J. Kuhar (1981a) Cholecystokinin receptors: Presence and axonal flow in the rat vagus nerve. Life Sci. 29: 697-705.

Zarbin, M. A., R. B. Innis, .J. K. Wamsley, S. H. Snyder, and M. J. Kuhar (1981b) Autoradiographic localization of CCK receptors in guinea pig brain. Eur. J. Pharmacol. 71: 349-350.

Zetler, G. (1980a) Anticonvulsant effects of caerulein and cholecystokinin octapeptide, compared with those of diazepam. Eur. J. Pharmacol. 65: 297-300.

Zetler, G. (1980b) Effects of cholecystokinin-like peptides on rearing activity and hexobarbital-induced sleep. Eur. J. Pharmacol. 66: 137-139.

Zetler, G. (1980c) Analgesia and ptosis caused by caerulein and cholecystokinin-octapeptide. Neuropharmacology 19: 415422.

Zetler, G. (1981) Central depressant effects of caerulein and cholecystokinin-like octapeptide differ from those of diazepam and haloperidol. Neuropharmacology 20: 277-283. 